\title{
Environmental efficiency measurement when producers control pollutants under heterogeneous conditions: a generalization of the materials balance approach
}

\author{
Andreas Eder (1D ${ }^{1}$ \\ Accepted: 11 December 2021 / Published online: 19 January 2022 \\ (c) The Author(s) 2022
}

\begin{abstract}
This article provides a generalization of the materials balance-based production model introduced by Coelli et al. (2007). Based on this, some new environmental efficiency (EE) measures are presented. The Coelli et al. (2007) EE measure and its extension by Rødseth (2016) produce biased efficiency estimates if the material flow coefficients (MFCs) are heterogeneous across decision-making units and non-discretionary. Furthermore, the Coelli et al. (2007) measure fails to reward emission reductions by emission control. To overcome these shortcomings, this paper proposes production models which allow for heterogeneous MFCs reflecting differences of external environmental factors or non-controllable heterogeneities in inputs and outputs, and which properly take into account emission abatement activities. Based on this, EE measures are provided and decomposed into (i) a part reflecting emission control efficiency (ECE), (ii) a part measuring material input efficiency (MIE), and (iii) a part reflecting the efficient allocation between material and non-material inputs (environmental allocative efficiency, EAE). The approach is illustrated by an empirical application to arable farming in Austria utilizing data from 90 farms for the year 2011. Soil erosion is considered an undesirable output and land a material input. The average EE, ECE, MIE, and EAE are 0.53, 0.96, 0.69, and 0.79, respectively. The results indicate that actual output can be potentially achieved with $47 \%$ less soil loss. Most of the potential to improve EE is due to differences in MIE and EAE. Removing inefficiencies in the implementation of existing, subsidized erosion controls allows soil loss to be reduced by $4 \%$.
\end{abstract}

JEL Classification C61·D24 $\cdot \mathrm{Q} 12 \cdot \mathrm{Q} 15$

Keywords Emission-generating technologies $\cdot$ Materials balance condition $\cdot$ Weak-G disposability $\cdot$ Data envelopment analysis $\cdot$ Non-discretionary factors $\cdot$ Soil erosion $\cdot$ Crop farms

\section{Introduction}

Multiple approaches to incorporate environmental perspectives into productivity and efficiency analysis exist (see Dakpo et al. 2016 for a survey of the literature): (i) Färe et al. (1986, 1989) were the first to introduce

Andreas Eder

andreas.eder@boku.ac.at

1 Institute for Sustainable Economic Development, Department of Economics and Social Sciences, University of Natural Resources and Life Sciences, Feistmantelstrasse 4, 1180 Vienna, Austria undesirable outputs (bad outputs) into an empirical production model, allowing for inefficiencies. They treat bad outputs as weakly disposable outputs; (ii) Hailu and Veeman (2001) model bad outputs as strongly disposable inputs; (iii) Lovell et al. (1995) and Seiford and Zhu (2002) transform bad outputs and model the transformed values as strongly disposable outputs; (iv) the ecoefficiency approach by Kuosmanen and Kortelainen (2005) ignores inputs and only considers good and bad outputs; (v) recently, the by-production approach that models polluting technology as the intersection of multiple sub-technologies has been introduced (Murty et al. 2012) and extended (Serra et al. 2014; Dakpo 2016; Ray et al. 2018; Lei 2020), and its application has gained 
popularity (see e.g., Dakpo et al. 2017; Ait Sidhoum et al. 2020). ${ }^{1}$

All these approaches have been criticized for various reasons (see, e.g., Färe and Grosskopf 2004; Førsund 2009; Dakpo et al. 2016; Førsund 2018; Hampf 2018). The most widely applied approaches, for example, (i) and (ii), are criticized for not complying with physical laws (i.e., the materials balance principle, law of mass conservation, or first law of thermodynamics) and for allowing for physically impossible production possibilities (Färe and Grosskopf 2003; Coelli et al. 2007; Førsund 2009; Hoang and Coelli 2011; Podinovski and Kuosmanen 2011; Rødseth 2017). To overcome this problem, Coelli et al. (2007) and Rødseth (2017) introduced production models that insure consistency with the materials balance principle. ${ }^{2}$ These models rely on the materials balance equation (MBE), an accounting identity that describes the relationship between potentially polluting by-products (residuals) of a production process, the amount of inputs used, and the amount of good outputs produced. Residuals (i.e., pollutants or bad outputs), inputs and good outputs are linked by material flow coefficients (MFCs) such that the amount of materials tied up in the inputs must equal the amount of the flow of materials embedded in intended outputs plus residuals.

Due to non-homogeneity in inputs and outputs and the role of some external factors, the MFCs may differ from one decision-making unit (DMU) to another (Dakpo et al. 2016). Although the MBE-based models have been applied in numerous efficiency analyses, especially in agriculture (see e.g., Hoang and Rao 2010; Hoang and Coelli 2011; Hoang and Alauddin 2012; Nguyen et al. 2012; Hoang and Nguyen 2013) and energy generation (see e.g., Welch and Barnum 2009; Hampf and Rødseth 2015, 2017, 2019), heterogeneous MFCs have received little attention in the literature. An exception is Hampf and Rødseth (2019). Their model accommodates heterogeneous MFCs that reflect differences in input qualities across DMUs. They assume that the input quality can be freely chosen by DMUs and, as such, the MFCs are considered controllable.

The study at hand extends the Coelli et al. (2007) model and the weak G-disposability technology introduced by Rødseth (2017), allowing for heterogeneous MFCs which reflect differences of some non-discretionary, environmental/ external factors. These models can also be applied to situations where input and output quality is heterogeneous across DMUs but non-controllable (i.e., input or output quality switching, such as fuel switching from coal to gas is not

\footnotetext{
${ }_{1}$ Multi-equation modeling of good and bad outputs was also established by Førsund $(2009,2018)$ building on the ideas of Frisch (1965).

2 The materials balance principle was introduced by Ayres and Kneese (1969) and Kneese et al. (1970) in the economic literature but, according to Pethig (2003), has been stepmotherly treated therein.
}

possible). Contrary to that of Hampf and Rødseth (2019), the approach presented in this article accounts for emission abatement activities that require the use of additional inputs. While network technologies (see e.g., Färe et al. 2013; Hampf 2014; Lozano 2015; Bostian et al. 2016, 2019; Bi et al. 2018) separately model the production and the abatement stages, our approach models the amount of abated emission as strongly disposable output together with all other inputs and outputs in a single stage. Inputs are jointly consumed by desirable output production and emission control. Hence, the procedure does not require information on the amount of inputs devoted to each of these processes.

Based on these extended production models, conditional data envelopment analysis (DEA) estimators of environmental efficiency (EE) are proposed that (i) reward emission reductions from emission control and (ii) control for environmental factors influencing the production of the bad output. The latter is achieved by introducing conditional technology sets that depend on nondiscretionary factors and restrict the reference set of the DMUs under evaluation to DMUs that face comparable environments (cf. Ruggiero 1996, 1998). This guarantees that differences in EE are not confused with differences in non-discretionary factors.

The presented procedure is a generalization of the MBEbased approach introduced by Coelli et al. (2007). It is shown that the Coelli et al. (2007) measure is a special case of the EE measures proposed here. Similarly to Rødseth (2016) and Wang et al. (2018), the EE measures are decomposed into three components that reveal the sources of inefficiencies with regard to emission generation. Taking the production of desirable outputs as given, the components reflect inefficiencies associated with (i) too low of an amount of abated emission for the given amount of inputs used, (ii) too much usage and misallocation of polluting inputs, and (iii) an unfavorable allocation between polluting and non-pollution inputs.

The approach is illustrated by an empirical application to arable farming using data from 90 Austrian crop farms for the year 2011, and considering soil erosion by water as an unintended, potentially polluting by-product that should be minimized. Soil erosion results from energy transmitted from wind or rainfall and leads to the loss of topsoil and soil organic matter, which are essential for plant growth. Soil erosion is the most important cause of soil degradation, which is recognized as one of the most pressing problems facing humanity (Young et al. 2015) and a serious threat to sustainable development as envisaged in the European Union (EU) Sustainable Development Strategy (EC 2001) and the Sustainable Development Goals of the United Nations (Griggs et al. 2013; Keesstra et al. 2018). The private and social costs of soil erosion are considerable, including reduced soil 
productivity and off-site effects, such as sedimentation, flooding, landslides, and water eutrophication (Pimentel et al. 1995; Adhikari and Nadella 2011; Graves et al. 2015; Panagos et al. 2018). Clearly, agriculture plays a key role, as agricultural land accounts for $68.3 \%$ of total soil loss in Europe (Panagos et al. 2015c). Considering that actual soil erosion rates for tilled, arable land in Europe are, on average, 3-40 times greater than the upper limit of tolerable soil erosion (Verheijen et al. 2009), the application gains particular importance.

Besides farmers' land use and management decisions, including crop choice and applied erosion control measures, the degree of soil loss mainly depends on exogenous environmental (non-discretionary) factors, such as rainfall quantity and intensity, soil texture and structure, and slope gradient and length. To the best of my knowledge, attempts to consider soil erosion as undesirable output in empirical production models are restricted to frontier eco-efficiency studies (see Picazo-Tadeo et al. 2012a, 2012b, 2014; Eder et al. 2021) in the mode of Kuosmanen and Kortelainen (2005), an approach that completely ignores inputs and fails to capture all the input substitution possibilities that could help to optimize environmental performance (Dakpo et al. 2016). Hence, this is the first study modeling soil erosion as an undesirable output within a production theoretical framework that simultaneously accounts for inputs, desirable outputs, and undesirable outputs.

\section{Materials balance equation}

The MBE introduced in the economic literature by Ayers and Kneese (1969) is a simplified form of the first law of thermodynamics and states that during a production process material cannot disappear. A general discussion and justification for incorporating the MBE in production analysis can be found in Lauwers (2009). Using empirical data as well as results from Monte Carlo simulations, Hampf (2018) finds that ignoring the physical restrictions imposed by the MBE when estimating technology sets, leads to seriously biased efficiency results. Moreover, the same study also shows that, even in the case of misspecifications, models based on the MBE outperform models which ignore the physical restrictions.

The MBE implies that the amount of materials bound in inputs equals the amount of materials bound in intended outputs and residuals (i.e., emissions or pollutants). Consider the situation in which we have a firm that produces a vector $m=1,2, \ldots, M$ desirable outputs, $y \in \mathbb{R}_{+}^{M}$, using a vector of $k=1,2, \ldots, K$ inputs, $x \in \mathbb{R}_{+}^{K}$. The input vector is partitioned into a sub-vector of $S$ material inputs, $x^{P} \in \mathbb{R}_{+}^{S}$, and a sub-vector of $\mathrm{K}-S$ non-material inputs, $x^{N P} \in \mathbb{R}_{+}^{K-S}$. The production activity causes the emission of potentially polluting substances as a by-product. The amount of emissions is defined by the MBE

$b^{u c}=u x-v y$.

Equation (1) represents uncontrolled emissions, where $u \in \mathbb{R}_{+}^{K}$ and $v \in \mathbb{R}_{+}^{M}$ are row vectors of known nonnegative constants representing the MFCs of inputs and desirable outputs. Material inputs (i.e., polluting inputs) have MFCs that are positive and non-material inputs (i.e., non-polluting inputs) are associated with MFCs that are zero. If desirable outputs are taken as given, emissions can be reduced by using fewer material inputs or by substituting polluting with non- or less-polluting inputs. Another strategy to reduce uncontrolled emissions is the use of emission abatement activities that require the use of additional inputs. This is formalized by Eq. (2) as follows:

$b^{c}=u x-v y-a$.

Equation (2) represents controlled emissions, that is, the amount of uncontrolled emissions reduced by emission control. The abatement output $a \in \mathbb{R}_{+}$is the amount of emission avoided by emission control. Eq. (2) is linear in inputs and outputs, but one can also formulate a non-linear relationship (Pethig 2006).

\section{Literature review}

Table 1 provides an overview of MBE-based production models and their features. Coelli et al. (2007) consider the

Table 1 Review of MBE-based models

\begin{tabular}{llll}
\hline Model & With emission control & MFCs heterogeneous across DMUs & MFCs controllable \\
\hline Coelli et al. (2007) & No & No & Not relevant \\
Rødseth (2016) & Yes & No & Not relevant \\
Wang et al. (2018) & Yes & No & Not relevant \\
Hampf and Rødseth (2019) & No & Yes & Yes \\
The new models in this article & Yes & Yes & No \\
\hline
\end{tabular}

$M B E$ materials balance equation, $M F C s$ material flow coefficients 
output vector $y$ as fixed and minimize the uncontrolled emission in Eq. (1) by choosing the optimal input vector $x$ subject to a traditional production technology. The model insures that the MBE is satisfied by considering Eq. (1) explicitly as the objective function of the optimization problem. However, the model by Coelli et al. (2007) ignores emission abatement activities that usually require the use of additional inputs. Hence, the EE measure proposed by Coelli et al. (2007) provides biased efficiency rankings if emission control is a common compliance strategy (cf. Rødseth 2016).

To overcome this problem, Rødseth (2016) proposes a new EE measure that rewards emission reductions by emission control and shows that the new efficiency measure coincides with Coelli et al.'s (2007) efficiency measure if none of the considered DMUs control emissions and the MFCs of the desirable outputs are zero. Contrary to the initial approach of Coelli et al. (2007), which considers the MBE as the objective function of a minimization problem, Rødseth (2016) imposes a set of axioms on the production technology to insure that the MBE shown in Eq. (2) holds for all production points within the production possibility set (PPS). This weak G-disposability technology is described and compared with other modeling approaches of production technologies, in particular the modeling of bad outputs as weakly disposable (Färe et al. 1986, 1989), in Rødseth (2017). The weak G-disposability technology allows the specification of a production model that includes controlled emissions as undesirable outputs.

Wang et al. (2018) extend the work of Rødseth (2016) by allowing for multiple bad outputs that can be either controllable or non-controllable. They propose some new measures of EE and abatement efficiency, and provide measures and decompositions of environmental and abatement efficiency change based on global Malmquist productivity indices. However, the suggested environmental and abatement efficiency measures are based on a somewhat questionable objective function: Wang et al. (2018) aggregate all bad outputs into a single measure by considering the minimization of the average value of all bad outputs. Contrary to Rødseth (2016) the technology estimator in Wang et al. (2018) allows for non-zero slacks in the abatement outputs.

However, until recently, heterogeneous MFCs have received little attention in the literature. The approach of Coelli et al. (2007) and Rødseth (2016) were originally applied to situations where MFCs are homogeneous across all DMUs. Welch and Barnum (2009) apply the model of Coelli et al. (2007) to electricity generation and maintain the assumption of homogeneous MFCs. Nguyen et al. (2012) uses the approach of Coelli et al. (2007) to measure the nutrient use efficiency of South Korean rice farms and apply heterogeneous MFCs reflecting differences in the eutrofying power of fertilizers across DMUs. However, the consequences for EE measurement when comparing farms which use fertilizers with different nutrient content are not discussed. ${ }^{3}$

Hampf and Rødseth (2019) are the first to explore the consequences of heterogeneous MFCs for EE measurement. Differences in MFCs across DMUs are interpreted as differences in input qualities. They find that failing to control for this heterogeneity leads to performance measurement errors, that is, input quality differences are confused with technical inefficiency. Also, they develop a production model that accounts for heterogeneous MFCs. Based on this model, a measure of EE is proposed that is decomposed into a part reflecting input quality and a part reflecting technical efficiency. This approach is applied to evaluate the EE of coal-fired power plants in the United States using a panel dataset covering the years 1997 to 2015. Carbon dioxide $\left(\mathrm{CO}_{2}\right)$ and sulfur dioxide $\left(\mathrm{SO}_{2}\right)$ are considered undesirable outputs. The power plants use different qualities of coal with varying sulfur and carbon contents, which are captured by heterogeneous MFCs. It is assumed that DMUs can switch among inputs of different quality (coal types), and choosing a suboptimal input (coal) quality is reflected by a lower EE. However, fuel switching is not always possible. For instance, the decision on which type of coal is used depends on the location of the power plant, transportation costs, and the sulfur content of coal. These factors are likely to be uncontrollable by the power plant operators. When evaluating the EE of power plants that use even more heterogeneous types of fuel, for example, coal and gas (cf. Welch and Barnum 2009), the assumption that fuel switching is feasible is even more questionable. ${ }^{4}$

In addition, there are situations where heterogeneous MFCs do not result from differences in input quality, but rather reflect heterogeneous environmental factors, also known as non-discretionary variables or Z-variables (cf. Ruggiero 1998), which govern the transformation of inputs into good and bad outputs. For instance, consider the use of arable land to produce agricultural commodities. The usage of arable land in the production process inevitably causes soil erosion by water and wind. The degree of soil loss depends on exogenous environmental factors, such as

\footnotetext{
$\overline{3}$ If switching from urea fertilizers to complex fertilizers is constrained by manure management, the estimated potentials to reduce the eutrofying power of the farms are seriously overestimated. Furthermore, technical efficiency variations are mixed up with differences in fertilizer quality.

4 A coal boiler is usually designed to burn coal, not natural gas. Even if a coal plant were modified to accept natural gas, the resultant fuel efficiency would be low and production costs would remain elevated.
} 
rainfall quantity and intensity, soil texture and structure, and slope gradient and length. ${ }^{5}$

The examples given above describe production processes where the MFCs are heterogeneous across DMUs but uncontrollable by the operators, at least to a certain extent. Assuming that MFCs are controllable in such situations leads to biased efficiency estimates, and inefficiencies are confused with non-discretionary factors. To account for this, the production models presented in this study extend the approach of Coelli et al. (2007) and Rødseth (2016) to account for heterogeneous and non-discretionary MFCs. In contrast to Hampf and Rødseth (2019), focusing on uncontrolled emissions, the new models allow for emission control and the substitution of polluting inputs with nonpolluting inputs.

\section{Methodology}

This section presents two approaches for theoretical modeling and estimating the production technology as well as measuring the EE of DMUs that control emissions and have homogeneous MFCs. The first approach extends the Coelli et al. (2007) production model by an abatement output, and the second approach was introduced by Hampf and Rodseth (2015) and Rødseth (2016, 2017). These two approaches deliver identical solutions under quite general conditions. We can exploit this useful property for EE measurement of DMUs with heterogeneous and non-discretionary MFCs. In addition, I discuss the consequences of uncontrollable differences in MFCs across DMUs for the production possibilities and demonstrate how EE can be evaluated and decomposed in such situations.

Throughout this section, it is assumed that we observe $i=1,2, \ldots, N$ DMUs that produce a vector of $m=1,2$, ..., $M$ desirable outputs, $y_{i} \in \mathbb{R}_{+}^{M}$ using a vector of $k=1$, $2, \ldots, K$ inputs, $x_{i} \in \mathbb{R}_{+}^{K}$. The input vector is partitioned into a sub-vector of $S$ material inputs, $x_{i}^{P} \in \mathbb{R}_{+}^{S}$, and a sub-vector of $K-S$ non-material inputs, $x_{i}^{N P} \in \mathbb{R}_{+}^{K-S}$. While the MFCs of material inputs are strictly positive, the MFCs of non-material inputs are zero. Similarly, the MFCs of desirable outputs containing material mass are strictly positive and the MFCs are zero for desirable outputs that do not contain material mass. The DMUs control emissions, where $a_{i} \in \mathbb{R}_{+}$is the amount of prevented emission by emission control (i.e., a desirable

\footnotetext{
5 In addition, the extent of soil loss is also determined by farmers' land use and management decisions. In particular, appropriate crop choice and erosion control measures can reduce soil erosion rates (Pimentel et al. 1995; Panagos et al. 2015a; Panagos et al. 2015b).
}

output) and $b_{i}^{c} \in \mathbb{R}_{+}$is the controlled emission (i.e., an undesirable output). ${ }^{6}$

\subsection{Production with homogeneous MFCs}

\subsubsection{Modeling and estimating the production technology}

Consider a traditional production technology which is extended by an abatement output (desirable output) $a \in \mathbb{R}_{+}$, ignoring the controlled emission (undesirable output) $b^{c} \in \mathbb{R}_{+}$

$T_{1}=\left\{\langle x, y, a\rangle \in \mathbb{R}_{+}^{K+M+1} \mid x\right.$ can produce $\left.(y, a)\right\}$.

As emphasized by Coelli et al. (2007), the abatement output should be a good output variable, not a bad output variable. ${ }^{7}$ For estimating $T_{1}$ from empirical data, it is assumed that the input vector $x$ can be employed both to desirable output production and emission control activities. Furthermore, the standard axioms of a neo-classical production model are assumed to hold. ${ }^{8}$ In particular, outputs are assumed to be freely disposable, which means that an increase, for example, in the abatement output takes place at the expense of at least one other output when the production is efficient.

Next, consider a traditional production technology that is extended by a controlled emission (undesirable output) $b^{c} \in \mathbb{R}_{+}$. The abatement output (desirable output) $a \in \mathbb{R}_{+}$is not a separate variable as in Eq. (3) but is taken into account only indirectly via $b^{c}$ (cf. Eq. (2)).

$T_{2}=\left\{\left\langle x, y, b^{c}\right\rangle \in \mathbb{R}_{+}^{K+M+1} \mid x\right.$ can produce $\left.\left(y, b^{c}\right)\right\}$.

To estimate $T_{2}$ from empirical data, Rødseth (2017) introduces the weak-G disposability technology assuming that $T_{2}$ is a non-empty, closed, convex set that is bounded from above and that there is no free lunch. In addition to these standard axioms of neoclassical production technologies, three further axioms are assumed to hold: (i) input essentiality, (ii) output essentiality, and (iii) weak-G disposability. The essentiality axioms state that polluting inputs cannot completely be transformed into good outputs, and thus, the use of polluting inputs inevitably results in the

\footnotetext{
${ }^{6}$ Note that the model presented in this article considers only one undesirable output. However, the approach can be generalized to multiple bad outputs following the procedure outlined in Coelli et al. (2007).

7 Note that this extension of the model by Coelli et al. (2007) requires exactly the same data as the model by Rødseth (2016). If the controlled emissions, inputs, outputs, and the MFCs are known, the abatement output can be calculated by using Eq. (2).

${ }^{8} T_{1}$ is a non-empty, closed, and convex set that is bounded from above (output boundedness). There is no free lunch, and inputs and outputs are freely disposable. For details see, for example, Färe and Primont (1995).
} 
production of polluting by-products. In addition, these pollutants can only result from the production process if polluting inputs are used. The weak-G disposability axiom guarantees that the disposal of inputs and outputs takes place according to the MBE.

To estimate $T_{1}$ and $T_{2}$, the nonparametric DEA estimator by Banker et al. (1984) and Hampf and Rødseth (2015) is applied, respectively. In contrast to parametric methods, DEA does not impose a specific functional form on the technology set, but estimates a piecewiselinear approximation of the technology frontier based on the above defined axioms. The DEA estimator for $T_{1}$ is defined as

$$
\widehat{T}_{1}=\left\{\begin{array}{l}
\langle x, y, a\rangle \in \mathbb{R}_{+}^{K+M+1} \mid x^{k}=\sum_{i=1}^{N} \lambda_{i} x_{i}^{k}+\varepsilon_{x^{k}}, k=1, \ldots, K ; \\
y^{m}=\sum_{i=1}^{N} \lambda_{i} y_{i}^{m}-\varepsilon_{y^{m}}, m=1, \ldots, M ; a=\sum_{i=1}^{N} \lambda_{i} a_{i}-\varepsilon_{a} ; \\
\sum_{i=1}^{N} \lambda_{i}=1 ; \lambda_{i}, \varepsilon_{x^{k}}, \varepsilon_{y^{m}}, \varepsilon_{a} \geq 0, \forall i, k, m
\end{array}\right\} .
$$

The DEA estimator for $T_{2}$ is given by

$$
\widehat{T}_{2}=\left\{\begin{array}{l}
\left\langle x, y, b^{c}\right\rangle \in \mathbb{R}_{+}^{K+M+1} \mid x^{k}=\sum_{i=1}^{N} \lambda_{i} x_{i}^{k}+\varepsilon_{x^{k}}, k=1, \ldots, K ; \\
y^{m}=\sum_{i=1}^{N} \lambda_{i} y_{i}^{m}-\varepsilon_{y^{m}}, \quad m=1, \ldots, M ; b^{c}=\sum_{i=1}^{N} \lambda_{i} b_{i}^{c}+\varepsilon_{b^{c}} ; \\
\sum_{k=1}^{K} u^{k} \varepsilon_{x^{k}}+\sum_{m=1}^{M} v^{m} \varepsilon_{y^{m}}-\varepsilon_{b^{c}}=0 ; \\
\sum_{i=1}^{N} \lambda_{i}=1 ; \quad \lambda_{i}, \varepsilon_{x^{k}}, \varepsilon_{y^{m}}, \varepsilon_{b^{c}} \geq 0, \forall i, k, m
\end{array}\right\}
$$

In Eqs. (5) and (6), $\lambda_{\mathrm{i}}(i=1, \ldots, N)$ denotes the weight factors which are used to construct convex combinations of observations. Restricting them to sum up to unity implies that the technology satisfies variable returns to scale (VRS) (cf. Banker et al. 1984). A constant returns to scale (CRS) technology can be imposed by removing this restriction. All epsilons are slack variables. The slack variables $\varepsilon_{x^{k}}, \varepsilon_{y^{m}}, \varepsilon_{b^{c}}$ in $\widehat{T}_{2}$ are restricted according to the MBE. This summing up constraint on the slack variables guarantees that slacks in feasible input-output combinations are only part of $\widehat{T}_{2}$ if they satisfy the MBE.

\subsubsection{Measuring EE}

In this section, we benchmark the DMUs in terms of their ability to produce desirable outputs with a minimum of environmental damage. We minimize controlled emissions subject to (i) the production technology $T_{1}$ and (ii) the production technology $T_{2}$. Given the DEA estimator for $T_{1}$ in Eq. (5), the minimal emission for DMU $o$ can be estimated by solving the following linear programming problem (extension of Coelli et al.'s (2007) model)

$$
\begin{array}{ll}
\min _{\lambda, \varepsilon, a, x} & b_{I}^{c * * *}=\sum_{k=1}^{K} u^{k} x^{k}-\sum_{m=1}^{M} v^{m} y_{o}^{k}-a \\
\text { s.t } \quad x^{k}=\sum_{i=1}^{N} \lambda_{i} x_{i}^{k}+\varepsilon_{x^{k}}, \quad k=1, \ldots, K \\
y_{o}^{m}=\sum_{i=1}^{N} \lambda_{i} y_{i}^{m}-\varepsilon_{y^{m}}, \quad m=1, \ldots, M \\
a=\sum_{i=1}^{N} \lambda_{i} a_{i}-\varepsilon_{a} \\
\sum_{i=1}^{N} \lambda_{i}=1 \\
\lambda_{i}, \varepsilon_{x^{k}}, \varepsilon_{y^{m}}, \varepsilon_{a} \geq 0, \forall i, k, m .
\end{array}
$$

Given the DEA estimator for $T_{2}$ in Eq. (6), the minimal emission for DMU $o$ can be estimated by solving the following linear programming problem (Rødseth 2016)

$$
\begin{array}{ll}
\min _{\lambda, \varepsilon, b^{c}, x} & b_{I I}^{c * * *}=b^{c} \\
\text { s.t. } & x^{k}=\sum_{i=1}^{N} \lambda_{i} x_{i}^{k}+\varepsilon_{x^{k}} \quad k=1, \ldots, K \\
& y_{o}^{m}=\sum_{i=1}^{N} \lambda_{i} y_{i}^{m}-\varepsilon_{y^{m}}, \quad m=1, \ldots, M \\
& b^{c}=\sum_{i=1}^{N} \lambda_{i} b_{i}^{c}+\varepsilon_{b^{c}} \\
& \sum_{k=1}^{K} u^{k} \varepsilon_{x^{k}}+\sum_{m=1}^{M} v^{m} \varepsilon_{y^{m}}-\varepsilon_{b^{c}}=0 \\
& \sum_{i=1}^{N} \lambda_{i}=1 \\
& \lambda_{i}, \varepsilon_{x^{k}}, \varepsilon_{y^{m}}, \varepsilon_{b^{c}} \geq 0, \forall i, k, m .
\end{array}
$$

The linear programs are solved by choosing a feasible, emission minimizing combination of the polluting inputs, $x^{P}$, the non-polluting inputs, $x^{N P}$, and the abatement output, $a$, for producing the observed desirable outputs, $y_{o}$. Hence, the models allow for three emission reduction strategies: (i) emission reduction by increasing the abatement output, (ii) emission reduction by reducing and reallocating material inputs, and (iii) emission reduction by substituting material with non-material inputs. The EE measure for DMU $o$ based on Eqs. (7) and (8) is defined by the ratio of the minimal emission to the observed emission

$$
\begin{aligned}
& \mathrm{EE}_{I}=\frac{b_{I}^{c * * *}}{b_{o}^{c}} \\
& \mathrm{EE}_{I I}=\frac{b_{I I}^{c * * *}}{b_{o}^{c}} .
\end{aligned}
$$


Table 2 Data matrix of the soil erosion example with heterogeneous MFCs

Farm ID Abatement erosion ( $t$ ) Controlled erosion $(t)$ Uncontrolled erosion ( $t$ ) Material flow coefficient (t/ha) Share of abated erosion (\%)

\begin{tabular}{llllll}
\hline A & 2 & 3 & 5 & 0.5 & 40 \\
B & 3 & 2 & 5 & 0.5 & 60 \\
C & 4 & 6 & 10 & 1 & 40 \\
D & 6 & 4 & 10 & 1 & 60 \\
\hline
\end{tabular}

MFCs material flow coefficients. All farms use 10 ha land, $1000 \mathrm{~h}$ labor, and produce $100 \mathrm{t}$ of maize. The MFCs of maize are zero. The only erosion generating input with strictly positive MFCs is land

The EE measures take values greater than or equal to 0 and less than or equal to 1 , where one indicates that the DMU under consideration is efficient. The measure evaluates the DMU's possibility to reduce its controlled emission given its production of desirable outputs, $y_{0}$. This leads to the following propositions

Proposition 1: The minimal emissions obtained from Eq. (7), $b_{I}^{c * * *}$, and from Eq. (8), $b_{I I}^{c * * *}$ are identical if the slack of the abatement output in Eq. (7), $\varepsilon_{a}$, is zero. Hence, if $\varepsilon_{a}$ is zero, the EE measure of Rødseth (2016), $E E_{I I}$, and the new measure, $E E_{I}$, coincide. The formal proof is available in the Appendix A.

Proposition 2: Rødseth (2016) shows that his efficiency measure, $E E_{I I}$, is a generalization of the efficiency measure of Coelli et al. (2007) and coincides with the Coelli et al. (2007) measure, if none of the producers control emissions, and the MFCs of the desirable outputs are zero. It follows from this result and Proposition 1, that $E E_{I}$ coincides with the Coelli et al. (2007) measure if none of the producers control emissions, which implies that $a$ and $\varepsilon_{a}$ are zero for all DMUs, and the MFCs of the desirable outputs are zero. ${ }^{9}$

\subsection{Production with heterogeneous MFCs}

So far, we have assumed that the vector of MFCs for inputs, $u$, and outputs, $v$, consists of constants. Let us assume that the MFCs are non-discretionary and differ across DMUs. The vector of MFCs are represented by $u_{i}$ and $v_{i}$. The problem with ignoring heterogeneous, non-discretionary MFCs in EE measurement is illustrated by the following numerical example on soil erosion in arable farming.

Consider a farm that produces maize using the inputs land and labor. The usage of arable land in the production process causes soil erosion (an unintended output) by water and wind. The degree of soil loss by water depends on exogenous environmental factors, such as slope, slope length,

\footnotetext{
9 Note that Coelli et al. (2007) and Rødseth (2016) assume that the production technology exhibits constant returns to scale, while this article assumes a VRS technology. Proposition 1 and all further assertions that rely on comparisons of the production models of Coelli et al. (2007), Rødseth (2016), and the new models in this article are only valid if we assume that the returns to scale assumption is identical across these models.
}

and soil type of the fields as well as rainfall quantity and intensity. These differences in operating environments are captured by the heterogeneous MFCs of the single polluting input land. The MFC of land is the uncontrolled soil erosion in tons per hectare. Since labor is a non-polluting input, and maize does not contain any soil, the MFCs of labor and maize are zero. Farms implement erosion control measures to reduce erosion. These abatement activities (e.g., planting winter cover crops and using mulch tillage) require additional inputs and often result in higher production costs.

All farms in Table 2 employ the same amount of inputs, $10 \mathrm{ha}$ land and $1000 \mathrm{~h}$ labor, to produce the same amount of maize, 100 t. Farms A and B operate under more favorable conditions, for example, flatter fields than farms C and D resulting in lower MFCs, that is, $0.5 \mathrm{t} / \mathrm{ha}$ soil loss vs. $1 \mathrm{t} / \mathrm{ha}$. The farms also differ with respect to their share of abated erosion. Erosion control measures allow farms $\mathrm{A}$ and $\mathrm{C}$ to reduce uncontrolled erosion by $40 \%$, and farms B and D by $60 \%$.

The left-hand graph of Fig. 1 illustrates the measurement of EE following Eqs. (7) and (9), that is, assuming that MFCs are homogeneous across farms. ${ }^{10}$ Since farm D produces the highest abatement output, it is classified as environmentally efficient and spans the production frontier represented by the line $O D$ and its extension. All other farms are benchmarked against farm $\mathrm{D}$, resulting in an optimal abatement output of 6 t. However, this is not feasible for farms A and B operating under a more favorable environment than farm $\mathrm{D}$ and having an uncontrolled erosion of $5 \mathrm{t}$, compared with $10 \mathrm{t}$ for farm D. The optimal abatement output of $6 \mathrm{t}$ would result in a negative value of the optimal controlled erosion and in negative EE scores. Hence, Eq. (7) overestimates the potential of farms A and B to increase the abatement output. ${ }^{11}$

\footnotetext{
${ }^{10}$ Note that Fig. 1 shows CRS technology sets, while Eq. (7) and Eq. (9) assume a VRS technology. However, the reasoning associated with the numerical example and Fig. 1 is identical under a CRS and VRS technology.

${ }^{11}$ Note, that the abatement output is a fraction between zero and one of the uncontrolled emission, that is, $a=s b^{u c}=s(u x-v y), s \in[0,1]$. Hence, everything else being equal, farms operating under less favorable conditions, those with more unfavorable MFCs, can produce a higher abatement output in absolute terms.
} 

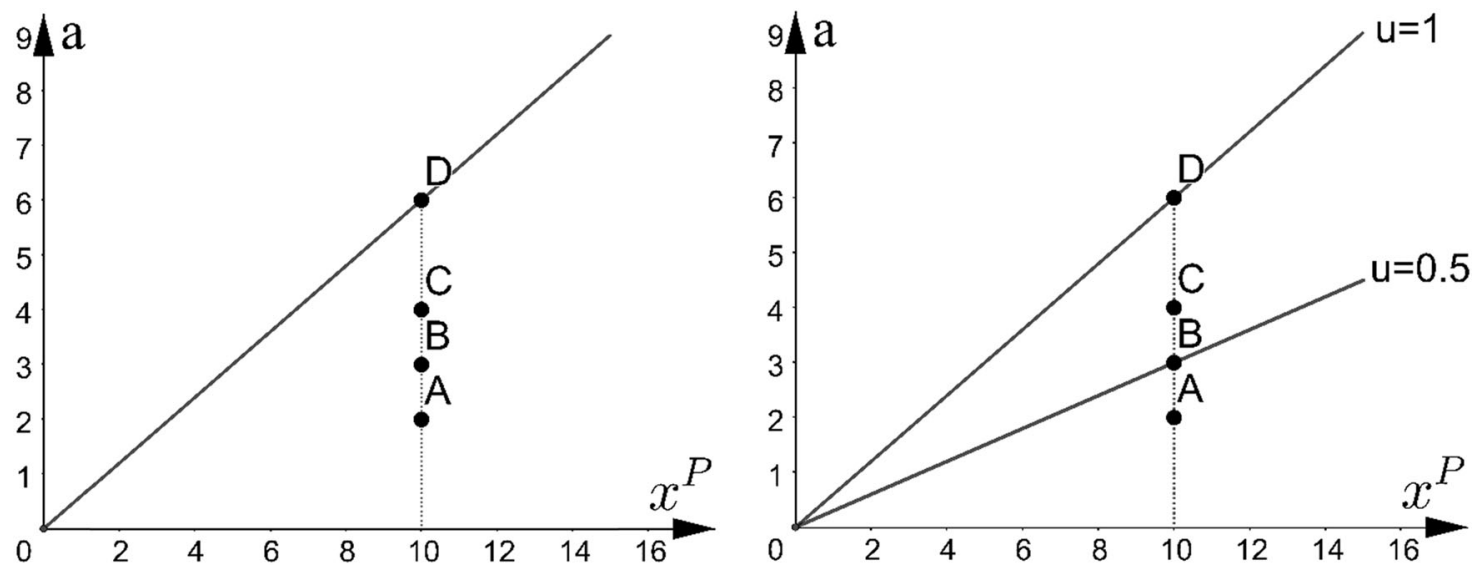

Fig. 1 EE measurement with heterogeneous MFCs. The left-hand (right-hand) graph shows the technology set(s) under constant returns to scale in line with Eq. (5) (Eq. [14]) ignoring (taking into account) the non-discretionary nature of the MFCs

The right-hand graph of Fig. 1 shows how to measure EE correctly. The idea is formalized by Eqs. (14), (18) and (25.1) in the next section. The heterogeneity and nondiscretionary nature of the MFCs is taken into account by estimating production frontiers and technology sets conditional on the MFCs. The line passing the origin to $D$ represents the production frontier for $u=1$, and the line $0 B$ and its extension represent the production frontier for $u=$ 0.5. Farms D and B, abating $60 \%$ of their uncontrolled erosion, are classified as environmentally efficient. Only farms having the same MFCs are compared with each other. Farm $\mathrm{C}$ is benchmarked against farm D, and farm $\mathrm{A}$ is benchmarked against farm $\mathrm{B}$, resulting in an optimal abatement output of $3 \mathrm{t}$ for farm $\mathrm{A}$ and $6 \mathrm{t}$ for farm $\mathrm{C}$. In accordance with Eq. (25.1), the EE of farms A and farm C, abating $40 \%$ of their uncontrolled erosion, is 0.66. Since there are no inefficiencies in the level and allocation of inputs, the EE scores reflect the erosion control performance of the farms. The scores are equal to the share of abated erosion $(40 \%)$ divided by the maximum observed value of this share $(60 \%)$.

The left-hand graph of Fig. 2 illustrates the EE measurement based on the weak G-disposability technology according to Eqs. (8) and (10). Contrary to technology, set $\widehat{T}_{1}$, shown in the left-hand graph of Fig. 1, the DEA estimator of the weak G-disposability technology, $\widehat{T}_{2}$, depends on the MFCs, which are part of the summing-up restriction on the slacks in Eq. (8). Hence, the PPS of the evaluated DMUs depends on their MFCs. This is shown in the left-hand graph of Fig. 2, depicting the PPS for $u=0.5$ and $u=1$ when holding the abatement output constant. Both sets are bounded by the solid line connecting $\mathrm{B}$ and $\mathrm{C}$. In the case of $u=0.5$, the PPS is additionally bounded by the dashed extensions with slope 0.5 . The technology set pivots upward if $u=1$, leading to different production possibilities. However, since the PPSs for $u=0.5$ and $u=1$ overlap, it is possible that DMUs with different MFCs are benchmarked against each other.

The left-hand graph of Fig. 2 shows that Farm B has the least amount of controlled emission and is, therefore, classified as environmentally efficient by Eq. (10). All other farms are benchmarked against farm B, resulting in a target for controlled erosion of $2 \mathrm{t}$. The $\mathrm{EE}$ of farm $\mathrm{C}$ is evaluated by $\mathrm{EE}_{I I}=\mathrm{PB} / \mathrm{PC}=2 / 6=0.33$. The same procedure applies to farms $\mathrm{A}$ and $\mathrm{D}$, having $\mathrm{EE}$ scores of 0.66 and 0.5 , respectively. The question is whether this is a fair ranking of environmental performance.

For instance, farm $\mathrm{D}$ reduces its uncontrolled erosion by the same share as farm B (i.e., by 60\%) using the same amount of inputs and producing the same amount of desirable outputs. The only difference between B and D is that D operates under less favorable environmental conditions (e.g., steeper slope of fields) leading to an uncontrolled (and controlled) soil loss that is twice that of farm B. Hence, farm $\mathrm{D}$ is punished for operating under harsher environmental conditions, and Eq. (8) overestimates the potential of farm D to decrease the controlled erosion.

To overcome this problem, I suggest that farms are only allowed to be benchmarked against DMUs operating in the same or a less favorable environment (i.e., having a $u$ higher or equal). This avoids that reduction potentials for controlled soil erosion are overestimated due to a comparison with DMUs operating in a more favorable environment (i.e., having a lower $u$ ).

Accordingly, the right-hand graph of Fig. 2 shows the PPS for $u=0.5$ and $u=1$. The PPS for $u=0.5$ remains unchanged, but the PPS for $u=1$ is now bounded by the solid line connecting D and $\mathrm{C}$ and the dotted extensions with slope 1. Farm A is again benchmarked against farm $B$ because they have the same MFCs. The EE of farm A is 0.66. Contrary to farm $\mathrm{A}$, the EE scores of farms $\mathrm{C}$ and $\mathrm{D}$ change compared with the situation depicted on the left-hand graph of Fig. 2. Farm D is classified as 

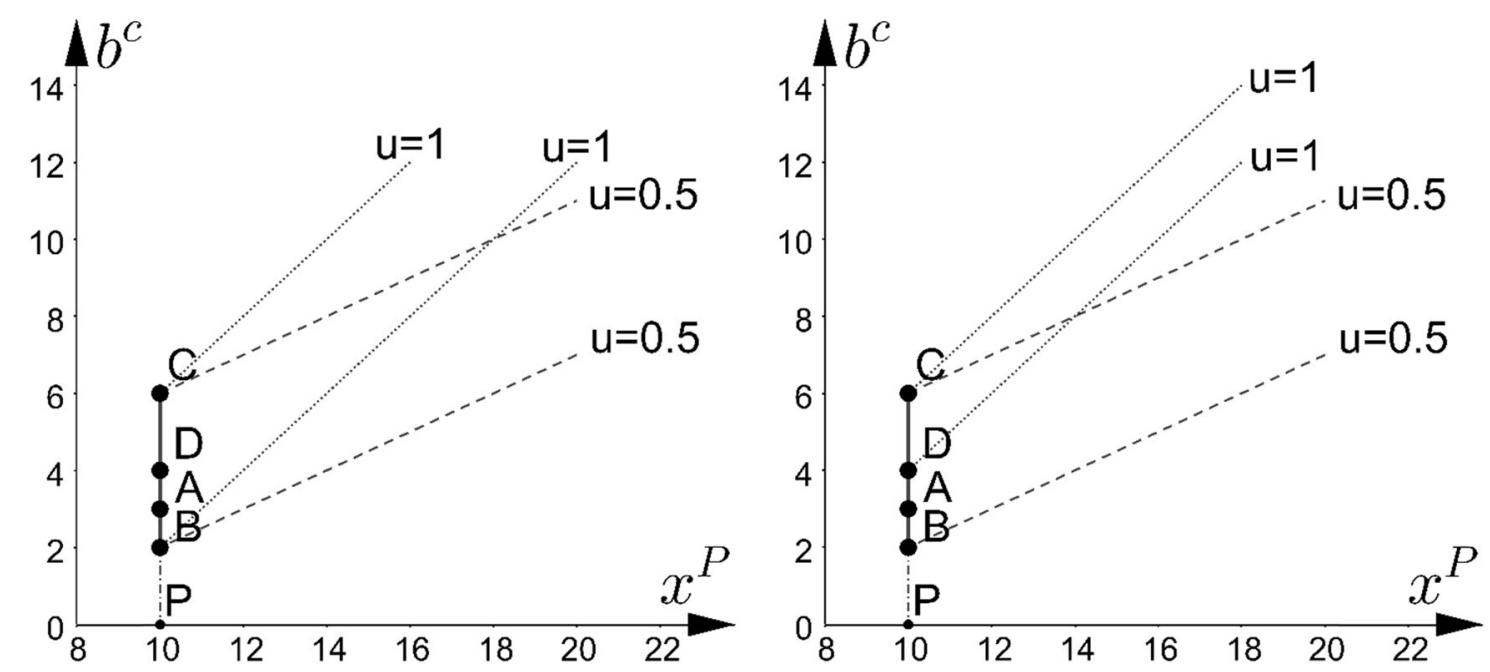

Fig. 2 EE measurement with heterogeneous MFCs. The left-hand (right-hand) graph shows the technology sets according to Eq. (6) (Eq. [15]) ignoring (taking into account) the non-discretionary nature of the MFCs

environmentally efficient, while farm $\mathrm{C}$ is benchmarked against farm D and has an EE of 0.66. Note that in this simple example, the EE scores obtained by the two new procedures presented in this section coincide (cf. right-hand graph of Figs. 1 and 2). The next two subsections clarify that, in general, the two approaches do not result in identical EE scores.

\subsubsection{Modeling and estimating the conditional production technology}

As shown in the last section, the non-discretionary MFCs affect the production of the abatement output and the uncontrolled emission. Everything else being equal, farms operating under less favorable conditions have a higher uncontrolled emission and can produce a higher abatement output, that is, the abatement output and the uncontrolled emission is increasing in $u$ and decreasing in $v .^{12}$ The following index of environmental harshness is proposed to measure the unfavorability of the MFCs

$$
\begin{aligned}
z_{i} & =\sum_{k=1}^{K} w_{i}^{k} u_{i}^{k}-\sum_{m=1}^{M} w_{i}^{m} v_{i}^{m}, \text { where, } \\
w_{i}^{k} & =\frac{u_{i}^{k} x_{i}^{k}}{\sum_{k=1}^{K} u_{i}^{k} x_{i}^{k}+\sum_{m=1}^{M} v_{i}^{m} y_{i}^{m}} \text { and } \\
w_{i}^{m} & =\frac{v_{i}^{m} y_{i}^{m}}{\sum_{k=1}^{K} u_{i}^{k} x_{i}^{k}+\sum_{m=1}^{M} v_{i}^{m} y_{i}^{m}} .
\end{aligned}
$$

The index $z_{i}$ is a weighted sum of the MFCs of inputs minus the weighted sum of the MFCs of desirable outputs. The proposed weights measure how much each input and desirable output contributes to the material flow (i.e., inflow plus

\footnotetext{
$\overline{12}$ This can easily be inferred from the fact that $a=s b^{u c}=s(u x-v y), s \in[0,1]$.
}

outflow). The sum of the weights is one: $\sum_{k=1}^{K} w_{i}^{k}+$ $\sum_{m=1}^{M} w_{i}^{m}=1 \quad$ for $\quad$ all $\quad i=1, \quad 2, \quad \ldots, \quad N$. A lower value of $z$ represents a more favorable environment, in the sense that less uncontrolled emissions are generated.

Consider a traditional production technology extended by an abatement output. The production technology depends on $z$, and the conditional PPS can be written as

$$
T_{1}(z)=\left\{\langle x, y, a\rangle \in \mathbb{R}_{+}^{K+M+1} \mid x \text { can produce }(y, a) \text { given } z(u, v)\right\} .
$$

Next, consider a traditional production technology that is extended by a controlled emission. The production technology depends on $z$, and the conditional PPS is given by

$$
T_{2}(z)=\left\{\left\langle x, y, b^{c}\right\rangle \in \mathbb{R}_{+}^{K+M+1} \mid x \text { can produce }\left(y, b^{c}\right) \text { given } z(u, v)\right\} .
$$

The production axioms described in Section 4.1.1 hold for $T_{1}(z)$ and $T_{2}(z)$. In addition, it holds that $T_{1}\left(z_{1}\right) \subseteq T_{1}\left(z_{2}\right)$ for all $z_{1} \leq z_{2}$. This axiom describes the relationship between the environment $\mathrm{z}$ and the PPS and is based on the ideas of Ruggiero (1996, 1998). In essence, this postulate allows the existence of nested PPSs and implies that a DMU with a less favorable environment, $z_{2}$, should be able to produce at least as much abatement output as any DMU with a more favorable environment, $z_{1}$. For $T_{2}(z)$, it is clear that a DMU with a more favorable environment, $z_{1}$, should be able to have a lower controlled emission for a given abatement output than a DMU with a less favorable environment, $z_{2} \cdot{ }^{13}$

\footnotetext{
${ }^{13}$ Note that, for both the PPS in Eq. (12) and Eq. (13), it is assumed that the production of $y$ is independent of $z$.
} 
Having these modifications in mind, it becomes clear that, if the production possibilities are defined in terms of $T_{1}(z)$, a given DMU should be compared only with DMUs with the same or a more favorable environment (i.e., DMUs having the same or a lower $z$ ). If the production possibilities are defined in terms of $T_{2}(z)$, a given DMU should be compared only with DMUs with the same or a less favorable/harsher environment (i.e., DMUs having the same or a higher $z$ ). While, in the case of $T_{1}(z)$, this procedure avoids an overestimation of the potential to increase the abatement output, in the case of $T_{2}(z)$, this avoids an overestimation of the potential to decrease the controlled emission.

For the empirical estimation of $T_{1}(z)$ and $T_{2}(z)$, we follow the procedure suggested by Ruggiero $(1996,1998)$ and restrict the set of possible reference units of a given DMU by introducing weight restrictions. The DEA estimator of $T_{1}(z)$ for DMU $o$ is given by

$$
\widehat{T}_{1}\left(z_{o}\right)=\left\{\begin{array}{l}
\langle x, y, a\rangle \in \mathbb{R}_{+}^{K+M+1} \mid x^{k}=\sum_{i=1}^{N} \lambda_{i} x_{i}^{k}+\varepsilon_{x^{k}}, k=1, \ldots, K ; \\
y^{m}=\sum_{i=1}^{N} \lambda_{i} y_{i}^{m}-\varepsilon_{y^{m}}, m=1, \ldots, M ; \quad a=\sum_{i=1}^{N} \lambda_{i} a_{i}-\varepsilon_{a} ; \\
\sum_{i=1}^{N} \lambda_{i}=1 ; \quad \lambda_{i}, \varepsilon_{x^{k}}, \varepsilon_{y^{m}}, \varepsilon_{a} \geq 0, \forall i, k, m \\
\lambda_{i} \geq 0 i: \quad z_{i} \leq z_{o} \\
\lambda_{i}=0 \quad \forall i: \quad z_{i}>z_{o}
\end{array}\right\} .
$$

The DEA estimator of $T_{2}(z)$ for DMU $o$ is given by

$$
\widehat{T}_{2}\left(z_{o}\right)=\left\{\begin{array}{l}
\left\langle x, y, b^{c}\right\rangle \in \mathbb{R}_{+}^{K+M+1} \mid x^{k}=\sum_{i=1}^{N} \lambda_{i} x_{i}^{k}+\varepsilon_{x^{k}}, k=1, \ldots, K ; \\
y^{m}=\sum_{i=1}^{N} \lambda_{i} y_{i}^{m}-\varepsilon_{y^{m}}, \quad m=1, \ldots, M ; b^{c}=\sum_{i=1}^{N} \lambda_{i} b_{i}^{c}+\varepsilon_{b^{c}} ; \\
\sum_{k=1}^{K} u_{o}^{k} \varepsilon_{x^{k}}+\sum_{m=1}^{M} v_{o}^{m} \varepsilon_{y^{m}}-\varepsilon_{b^{c}}=0 ; \\
\sum_{i=1}^{N} \lambda_{i}=1 ; \quad \lambda_{i}, \varepsilon_{x^{k}}, \varepsilon_{y^{m}}, \varepsilon_{b^{c}} \geq 0, \forall i, k, m \\
\lambda_{i} \geq 0 \quad \forall i: \quad z_{i} \geq z_{o} \\
\lambda_{i}=0 \quad \forall i: \quad z_{i}<z_{o}
\end{array}\right\}
$$

\subsubsection{Measuring and decomposing EE}

The optimization problems in the left and right column of Table 3 minimize the controlled emission of DMU $o$ subject to $\widehat{T}_{1}\left(z_{o}\right)$ and $\widehat{T}_{2}\left(z_{o}\right)$, respectively. The only abatement strategy allowed in Eqs. (16) and (19) is the increase of the abatement output for given desirable outputs and for fixed inputs. In addition, Eqs. (17) and (20) also allow reducing the emission by reducing and reallocating the material inputs, $x^{P}$, for given desirable outputs and fixed non-material inputs, $x^{N P}$. Finally, Eqs. (18) and (21) additionally allow for emission reduction by substituting material inputs with non-material.

While the target in Eqs. (16)-(21) is to minimize the controlled emission for given desirable outputs $y$ ("minimization approach"), another target could be to simultaneously reduce the controlled emission, rather than to minimize it, and increase the desirable output $y$ ("reduction approach"). Based on the ideas of Hampf and Rødseth (2015) it is possible to modify the optimization problems in Eqs. (16)-(21) to allow for a simultaneous increase in the desirable output $y$ and decrease in the controlled emission: Rather than minimizing the controlled emission, we would have to maximize the ratio of good output, $y$, to bad output, $b^{c}$, considering both good and bad output, as well as inputs as endogenous. This would result in a linearfractional program, which can be linearized by the Charnes-Cooper transformation (Charnes and Cooper 1962). Hampf and Rødseth (2015) propose a ratio efficiency measure given by the ratio of the estimated optimal good-output-bad-output ratio to the actual observed goodoutput-bad-output ratio.

Note that, while the reference set for DMU $o$ in Eqs. (16)-(18) is restricted to include only DMUs $i=1, \ldots$, $N$ with $z_{i} \leq z_{o}$, Eqs. (19)-(21) restrict the comparison set of DMU $o$ to include only DMUs $i=1, \ldots, N$ having $z_{i} \geq z_{o}$. Since the models in the left and right column of Table 3 deal with almost disjoint sets of possible reference units for DMU $o$, it should be clear that, in general, the solutions for each of the corresponding models do not coincide.

\begin{tabular}{|c|c|c|c|}
\hline Models based on $\widehat{T}_{1}\left(z_{o}\right)$ & & Models based on $\widehat{T}_{2}\left(z_{o}\right)$ & \\
\hline $\begin{array}{l}\min _{\lambda, \varepsilon, a} b_{1}^{c *}=\sum_{k=1}^{K} u_{o}^{k} x_{o}^{k}-\sum_{m=1}^{M} v_{o}^{m} y_{o}^{m}-a \\
\text { s.t } \quad\left(x_{o}, y_{o}, a\right) \in \widehat{T}_{1}\left(z_{o}\right)\end{array}$ & $(16)$ & $\begin{array}{ll}\min _{\lambda, \varepsilon, b^{c}} & b_{2}^{c *}=b^{c} \\
\text { s.t } & \left(x_{o}, y_{o}, b^{c}\right) \in \widehat{T}_{2}\left(z_{o}\right)\end{array}$ & $(19)$ \\
\hline $\begin{array}{l}\min _{\lambda, \varepsilon, a, x^{P}} b_{1}^{c * *}=\sum_{k=1}^{S} u_{o}^{k} x^{P, k}-\sum_{m=1}^{M} v_{o}^{m} y_{o}^{m}-a \\
\text { s.t } \quad\left(x^{P}, x_{o}^{N P}, y_{o}, a\right) \in \widehat{T}_{1}\left(z_{o}\right)\end{array}$ & $(17)$ & $\begin{array}{l}\min _{\lambda, \varepsilon, b^{c}, x^{P}} b_{2}^{c * *}=b^{c} \\
\text { s.t } \quad\left(x^{P}, x_{o}^{N P} y_{o}, b^{c}\right) \in \widehat{T}_{2}\left(z_{o}\right)\end{array}$ & $(20)$ \\
\hline $\begin{array}{ll}\min _{\lambda, \varepsilon, a, x} & b_{1}^{c * * *}=\sum_{k=1}^{K} u_{o}^{k} x^{k}-\sum_{m=1}^{M} v_{o}^{m} y_{o}^{m}-a \\
\text { s.t } \quad\left(x, y_{o}, a\right) \in \widehat{T}_{1}\left(z_{o}\right)\end{array}$ & $(18)$ & $\begin{array}{l}\min _{\lambda, \varepsilon, b^{c}, x} b_{2}^{c * * *}=b^{c} \\
\text { s.t } \quad\left(x, y_{o}, b^{c}\right) \in \widehat{T}_{2}\left(z_{o}\right)\end{array}$ & $(21)$ \\
\hline
\end{tabular}

Table 3 Linear programming problems (16)-(21) 
Furthermore, there is no rule which of the corresponding models give the optimal solution with the lowest controlled emission. For some evaluated DMUs, Eq. (18) detects improvement potentials, which are not detected by Eq. (21), and for other DMUs under evaluation exactly the opposite can be the case. Therefore, we consider the minimal value of the controlled emission of both, Eqs. (18) and (21), as the final solution: ${ }^{14}$

$b_{3}^{c * * *}=\min \left(b_{1}^{c * * *}, b_{2}^{c * * *}\right)$.

To get an exact decomposition of the EE measure (see Eq. (25.3)), the corresponding final solution for $b_{3}^{c * *}$ and $b_{3}^{c *}$ should be based on the same technology set as the final solution $b_{3}^{c * * *}$ in Eq. (22). For instance, if the final solution $b_{3}^{c * * *}$ in Eq. (22) is $b_{1}^{c * * *}$, which is based on $T_{1}\left(z_{o}\right)$, $b_{3}^{c * *}$ and $b_{3}^{c *}$ should also be based on $T_{1}\left(z_{o}\right)$ (i.e., $b_{3}^{c * *}=b_{1}^{c * *}$, $b_{3}^{c *}=b_{1}^{c *}$ based on Eq. (17) and Eq. (16)). If the final solution $b_{3}^{c * * *}$ in Eq. (22) is $b_{2}^{c * * *}, b_{3}^{c * *}$, and $b_{3}^{c *}$ should be based on $T_{2}$ $\left(z_{o}\right)$ (i.e., $b_{3}^{c * *}=b_{2}^{c * *}, b_{3}^{c *}=b_{2}^{c *}$ based on Eq. (20) and Eq. (19)). This can be formalized as follows:

$$
\begin{aligned}
& b_{3}^{c * *}= \begin{cases}b_{1}^{c * *} & \text { if } b_{1}^{c * * *}<b_{2}^{c * * *} \\
b_{2}^{c * *} & \text { if } b_{1}^{c * * *}>b_{2}^{c * * *}\end{cases} \\
& b_{3}^{c *}= \begin{cases}b_{1}^{c *} & \text { if } b_{1}^{c * * *}<b_{2}^{c * * *} \\
b_{2}^{c *} & \text { if } b_{1}^{c * * *}>b_{2}^{c * * *}\end{cases}
\end{aligned}
$$

Contrary to using only models based on either $\widehat{T}_{1}\left(z_{o}\right)$ or $\widehat{T}_{2}\left(z_{o}\right)$, the proposed procedure does not throw away valuable information. The estimated improvement potentials are based on a richer set of information and are therefore more accurate. The presented approach allows comparing the DMU under evaluation with all other DMUs in the sample, that is, the set of possible reference units of DMU $o$ is not restricted to a subset of DMUs as would be the case if only the models based on either $\widehat{T}_{1}\left(z_{o}\right)$ or $\widehat{T}_{2}\left(z_{o}\right)$ are applied. ${ }^{15}$

Based on the linear programming problems presented in Table 3 and the minimum model shown in Eqs. (22)-(24), the following measures of $\mathrm{EE}$ and its decompositions are introduced

$$
E E_{j}=\frac{b_{j}^{c * * *}}{b_{o}^{c}}=\frac{b_{j}^{c^{*}}}{b_{o}^{c}} \times \frac{b_{j}^{c * *}}{b_{j}^{c^{*}}} \times \frac{b_{j}^{c * * *}}{b_{j}^{c *}} \quad, j=1,2,3 .
$$

\footnotetext{
${ }^{14}$ Clearly, the final solution also includes the optimal input mix and abatement output corresponding to either Eq. (18) or Eq. (21).

15 My approach allows the reference point of DMU $o$ to be either a linear combination of DMUs with $z_{i} \leq z_{o}$ or $z_{i} \geq z_{o}$. Linear combinations of DMUs having $z_{i}<z_{o}$ and $z_{i}>z_{o}$ are ruled out as reference points.
}

The index $j=1,2,3$ indicates the EE measure and its decomposition based on $\widehat{T}_{1}\left(z_{o}\right), \widehat{T}_{2}\left(z_{o}\right)$, and the minimum model according to Eqs. (22)-(24), respectively. The overall efficiency measures and their components take values greater than or equal to 0 and less than or equal to 1 , where 1 indicates that the DMU under evaluation is efficient. The overall measures evaluate the DMU's potential to reduce its controlled emission, given its production of desirable outputs, while the components assess the contribution of different abatement strategies to the overall emission reduction potential. More specifically, the overall efficiency measures are decomposed into a part reflecting (i) emission reductions for given inputs and desirable outputs, which corresponds to the efficiency of the emission control activities (emission control efficiency, ECE), (ii) additional emission reductions by reducing and reallocating material inputs (material input efficiency, MIE), and (iii) further emission reductions by substituting material inputs with non-material inputs (environmental allocative efficiency, EAE).

As shown by Eq. (26), the procedure also allows decomposing the actual emission, $b_{o}^{c}$, into the optimal emission, $b_{o}^{c * * *}$, and emissions by source of inefficiency, that is, $L_{j}^{*}, L_{j}^{* *}$, and $L_{j}^{* * *}$. Where $L_{j}^{*}$ represents emissions due to inefficient implementation of emission control measures, $L_{j}^{* *}$ represents emissions resulting from inefficient use of material inputs, and $L_{j}^{* * *}$ reflects emissions due to inefficient allocation between material and nonmaterial inputs

$$
\begin{aligned}
& b_{o}^{c}=L_{j}^{*}+L_{j}^{* *}+L_{j}^{* * *}+b_{o}^{c * * *}, \quad j=1,2,3 \\
& \text { where, } \quad L_{j}^{*}=b_{o}^{c}-b_{j}^{c *}, \quad j=1,2,3 \\
& L_{j}^{* *}=b_{j}^{c *}-b_{j}^{c * *}, \quad j=1,2,3 \\
& L_{j}^{* * *}=b_{j}^{c * *}-b_{j}^{c * * *}, \quad j=1,2,3 .
\end{aligned}
$$

Last but not least, the relationship between the new EE measures in Eqs. (25.1)-(25.3) with the EE measures of Coelli et al. (2007) and Rødseth (2016) are explored in proposition 3:

Proposition 3: If the MFCs are homogeneous across all $D M U s$, Eq. (18) and Eq. (21) collapse into Eq. (7) and Eq. (8), respectively. It follows from this result and Proposition 1 and 2 that the new EE measures, $E E_{1}, E E_{2}$, and $E E_{3}$ are generalizations of the Coelli et al. (2007) measure and coincide with the Coelli et al. (2007) measure if the MFCs are homogeneous across all DMUs, none of the producers control emissions and the MFCs of the desirable outputs are zero.

Furthermore, the Rødseth (2016) EE measure is a special case of the new measures $\mathrm{EE}_{1}, \mathrm{EE}_{2}$, and $\mathrm{EE}_{3}$. The Rødseth (2016) measure coincides with the new measures if the MFCs are homogeneous across all DMUs and $\varepsilon_{a}$ in Eq. (18) is zero. 


\section{Empirical illustration}

This section applies the proposed methodology to the EE measurement of crop farms considering soil erosion as an undesirable output that has to be minimized. The approach is illustrated using a sample of 90 Austrian crop farms observed in 2011.

\subsection{Data}

Soil erosion estimates are based on a revised universal soil loss equation (RUSLE; Renard et al. 1997) using plot-level data from the Austrian Integrated Accounting and Control System (IACS). The calculation of all other inputs and outputs is based on farm bookkeeping data from the Austrian section of the EU's Farm Accountancy Data Network (FADN).

The RUSLE is expressed as $A=R K L S C P$, where $\mathrm{A}$ is the annual average soil loss from water in $t / h$ a per year for the area under investigation. As shown in the equation, A is determined by a multiplication of the rainfall erosivity factor (R-factor), soil erodibility factor (K-factor), slope length factor (L-factor), slope steepness factor (S-factor), cover-management factor (C-factor), and support practices factor (P-factor). While R-, K-, L-, and S-factors represent environmental conditions, such as precipitation, soil type, and topography, the $\mathrm{C}$ - and P-factors represent management practices of farmers. Since the desirable outputs are taken as given, we also consider the $\mathrm{C}$-factor, that is, crop choice, as fixed. The P-factor is considered as the single factor adjustable by the farmer.

The P-factor is a ratio which describes how implemented erosion control measures cause soil loss to deviate from losses that occur without the implementation of these measures (Panagos et al. 2015b). ${ }^{16}$ The erosion control measures considered in this study include i) mulch-till and no-till associated with a P-factor of 0.5 , meaning that soil erosion is reduced by $50 \%$ relative to conventional tillage, and ii) eight variants of winter cover crops differentiated by type of cover crop and duration of coverage associated with P-factors of $0.5-0.9 .{ }^{17}$

The farm-specific MFC for land, that is, the uncontrolled erosion in $\mathrm{t} / \mathrm{ha}$ per year, is estimated by $u=R K L S C$. The controlled erosion in tons is given by $b^{c}=R K L S C P L a n d$, where Land is the utilized agricultural area (UAA) in hectares. The abatement output in tons is estimated by

\footnotetext{
16 This study covers all erosion control measures subsidized by agrienvironmental schemes in Austria (cf. BMLFUW 2009). Additional non-subsidized measures applied by farmers cannot be taken into account due to data unavailability.

17 Values for P-factors are taken from Wpa GmbH and BWA (2009). Six wine- and fruit-specific erosion control measures are also considered. Since the sample only includes crop farms, those measures are of minor importance.
}

subtracting the controlled erosion from the uncontrolled erosion: $a=R K L S C L a n d(1-P) .{ }^{18}$

Information on implemented erosion control measures is derived from the IACS. The IACS provides parcel-level information for almost all agricultural parcels in Austria in terms of the main crops planted and implemented agrienvironmental schemes, including specific erosion control measures, such as tillage type (mulch-till and no-till) and different modes of soil coverage (type of cover crop and duration of coverage). This information allows us to assign a C- and a P-factor to each parcel (see Eder et al. 2021 for a complete list of $\mathrm{C}$ - and P-factors used in this study). For estimating R-, K-, L-, and S-factors, we follow Wpa GmbH and BWA (2009). Due to data availability and for the ease of exposition, we use cross-sectional data for the year 2011.

All other information is taken from the Austrian section of the EU's FADN. The farms included in the FADN dataset are a stratified sample, representing the Austrian agricultural sector in terms of standard output, production orientation, and altitude.

The dataset for the year 2011 consists of 2265 farms. However, this illustration focuses on specialized crop farms whose share of revenues from crops in total revenues is larger or equal to $65 \%$. In addition, to increase the homogeneity of the sample, farms whose share of revenues from potatoes and sugar beets in crop revenues is larger than $20 \%$ are excluded. This results in a sample of 114 crop farms in 2011. When merging FADN with IACS data, 23 observations are removed due to missing information on erosion control measures or differences in farms' UAA being larger than $20 \%$ between the FADN and IACS. Finally, based on the outlier detection method described in Bogetoft and Otto (2011) one farm is classified and removed as an outlier resulting in a sample of 90 farms for the year 2011 .

Table 4 provides descriptive statistics on input and output variables used in the DEA models as well as on the MFCs. The production factor land is measured by UAA in hectares and includes owned and rented land. UAA ranges from 10 to 166 ha, and $96 \%$ is arable land on average. Labor is measured in agricultural working units (AWUs), where one AWU is equal to 2160 working hours. Capital includes farm buildings, machinery, equipment, standing timber, livestock, and assets from activities related to farming (e.g., agri-tourism, renting out machinery, and services for other farms). Intermediate inputs cover expenditures for land use (e.g., seeds, fertilizer, and pesticides), livestock (e.g., fodder and veterinary), energy, insurance, and expenditures for

\footnotetext{
$\overline{18}$ A detailed description of the linkage between the RUSLE model and the MBE, as well as the derivation of the MFC for land is available in Appendix B.
} 
Table 4 Descriptive statistics of data used for analysis $(N=90)$

\begin{tabular}{|c|c|c|c|c|}
\hline Variables & Mean & SD & Min & Max \\
\hline \multicolumn{5}{|l|}{ Inputs } \\
\hline Land, UAA (ha) & 63.68 & 38.13 & 9.84 & 165.99 \\
\hline Labor (AWU) & 0.94 & 0.60 & 0.11 & 4.00 \\
\hline Capital (Euro, real) & $122,843.86$ & $86,321.91$ & 6766.88 & $449,625.45$ \\
\hline $\begin{array}{l}\text { Intermediate inputs } \\
\text { (Euro, real) }\end{array}$ & $22,954.78$ & $16,853.78$ & 2188.81 & $81,749.53$ \\
\hline \multicolumn{5}{|l|}{ Desirable outputs } \\
\hline $\begin{array}{l}\text { Total revenue } \\
\text { (Euro, real) }\end{array}$ & $54,960.45$ & $37,384.50$ & 937.55 & $159,368.36$ \\
\hline Abatement erosion $(\mathrm{t})$ & 18.72 & 33.41 & 0.00 & 180.37 \\
\hline \multicolumn{5}{|l|}{ Undesirable output } \\
\hline Controlled erosion $(t)$ & 162.97 & 187.53 & 4.33 & 1038.87 \\
\hline \multicolumn{5}{|c|}{ Material flow coefficient (land) } \\
\hline $\begin{array}{l}\text { Uncontrolled } \\
\text { erosion (t/ha) }\end{array}$ & 3.18 & 3.34 & 0.10 & 19.88 \\
\hline
\end{tabular}

Authors' calculations from Austrian FADN and IACS data. Data obtained from the Federal Ministry of Sustainability and Tourism. Note: The sample is a cross-section of 90 farms observed in 2011. $U A A$ utilized agricultural area, $A W U$ agricultural working unit. One AWU is 2160 working hours

other activities related to farming. Total revenues (desirable output) include earnings net of subsidies from plant production, livestock, forestry, services, direct marketing, financial income (e.g., insurance), and other activities related to farming. Capital, intermediate inputs, and total revenue are implicit quantity values, that is, the nominal values of the components of each variable are divided by proper price indices.

On average, the abatement output of a farm is $19 \mathrm{t}$, that is, erosion control measures reduce the soil loss by $19 \mathrm{t}$ on average which corresponds to a reduction of $10 \%$. However, there is a substantial variation in the abatement output. About $11 \%$ of the farms do not implement erosion control measures having a zero abatement output (or a P-factor of one). On the other end of the spectrum are farms reducing the uncontrolled soil loss by $50 \%$ through erosion control. The average MFC of land, that is, the average uncontrolled soil loss in $\mathrm{t} / \mathrm{ha}$ per year, is 3.2 and ranges from $0.1 \mathrm{t} / \mathrm{ha}$ to almost $20 \mathrm{t} / \mathrm{ha}$. The MFCs of all other inputs and outputs are assumed to be zero.

\subsection{Results}

Table 5 shows the descriptive statistics of the estimated EE scores and their components. Figure 3 completes this information by providing kernel density estimates of the efficiency distributions. Models 1-3 refer to the estimates based on $\widehat{T}_{1}\left(z_{o}\right)$ (i.e., Eqs. (16)-(18)), $\widehat{T}_{2}\left(z_{o}\right)$ (i.e., Eqs. (19)-(21)]), and the minimum model (i.e., Eqs. (22)-(24)), respectively.

The average EE is 0.54 in Model 1 , and 0.71 in Model 2. While Model 1 classifies $22 \%$ of the farms as environmentally efficient, Model 2 classifies $44 \%$ as efficient.
Table 5 Descriptive statistics of efficiency scores for Models 1-3 $(N=90)$

\begin{tabular}{lcll}
\hline Efficiency index & $\begin{array}{l}\text { Model 1 } \\
\text { Eq. (25.1) }\end{array}$ & $\begin{array}{l}\text { Model 2 } \\
\text { Eq. (25.2) }\end{array}$ & $\begin{array}{l}\text { Model 3 } \\
\text { Eq. (25.3) }\end{array}$ \\
\hline Environmental efficiency (EE) & & & \\
Geom. mean & 0.54 & 0.71 & 0.53 \\
SD & 0.27 & 0.26 & 0.26 \\
Min & 0.15 & 0.24 & 0.15 \\
Max & 1 & 1 & 1 \\
Number of efficient farms & 20 & 40 & 15 \\
Erosion control efficiency (ECE) & & & \\
Geom. Mean & 0.97 & 0.99 & 0.96 \\
SD & 0.05 & 0.04 & 0.06 \\
Min & 0.75 & 0.68 & 0.68 \\
Max & 1 & 1 & 1 \\
Number of efficient farms & 58 & 82 & 56 \\
Material input (land use) efficiency $($ MIE) & & \\
Geom. mean & 0.69 & 0.86 & 0.69 \\
SD & 0.27 & 0.20 & 0.27 \\
Min & 0.17 & 0.27 & 0.17 \\
Max & 1 & 1 & 1 \\
Number of efficient farms & 42 & 65 & 39 \\
Environmental allocative efficiency (EAE) & & \\
Geom. mean & 0.80 & 0.83 & 0.79 \\
SD & 0.21 & 0.21 & 0.21 \\
Min & 0.21 & 0.29 & 0.21 \\
Max & 1 & 1 & 1 \\
Number of efficient farms & 34 & 50 & 32 \\
\hline Desciptive statisics & & \\
\hline
\end{tabular}

Descriptive statistics of efficiency indices according to Eqs. (25.1)(25.3) are shown. Reported values are based on a sample of 90 Austrian crop farms observed in 2011

Hence, in this specific empirical example, Model 1 detects larger average inefficiencies than Model 2. Remember, the sets of possible reference units that are used for performance comparisons of a particular DMU in Model 1 and Model 2 are almost disjoint, which explains most of the differences in EE scores between the two models. Since the final EE (Model 3) represents the minimum value of the efficiency scores of Models 1 and 2, it is on average very close to that of Model 1 . The final average EE is 0.53 , meaning that the same amount of output can be potentially achieved with $47 \%$ less soil loss. Finally, about $17 \%$ of the farms are classified as environmentally efficient.

The graphical analysis in Fig. 3 is complemented by formal testing for the statistical significance of differences between the distributions of efficiency (EE, ECE, MIE, and EAE) obtained from Model 1-3. To compare the distributions, we implement the $\mathrm{Li}$ (1996) test and derive bootstrap estimates of the $p$-values based on a naive bootstrap procedure with 5000 replications. The results of the test are shown in Table 8 in Appendix C. The tests reveal that the distribution of EE, ECE, and MIE between Model 1 and Model 2 is significantly different at the $1 \%$ significance level. The hypotheses of equal distributions of EE, ECE, and MIE under Model 1 and Model 3 cannot be 
a) Kernel Density Estimates of Environmental Efficiency

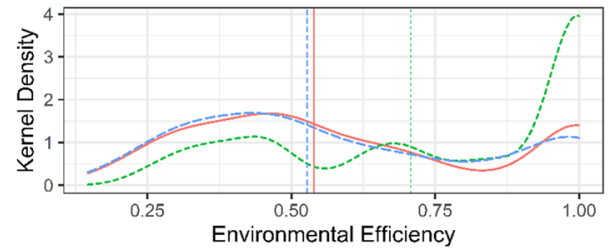

c) Kernel Density Estimates of Material Input Efficiency

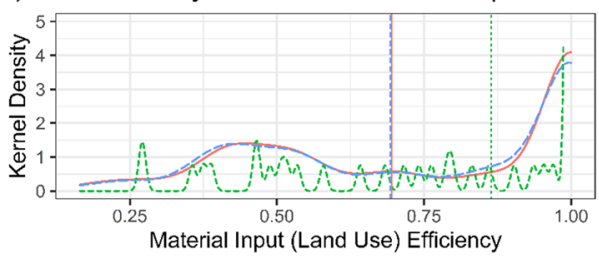

b) Kernel Density Estimates of Erosion Control Efficiency

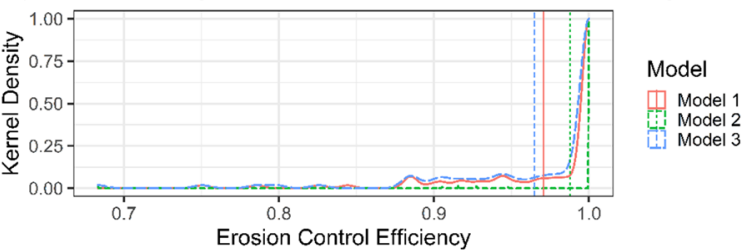

d) Kernel Density Estimates of Environmental Allocative Efficiency

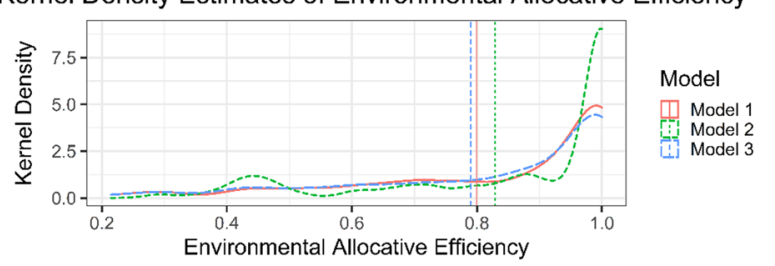

Fig. 3 Kernel density distributions of environmental efficiency and its components are shown. In each panel the solid, dashed and dotted curve is the distribution generated under Model 1, Model 2, and Model 3, respectively. The solid, dashed and dotted vertical line represents the geometric mean of the estimated efficiency scores under Model 1, Model 2, and Model 3, respectively. The kernel density shown in panel (b) is scaled to a maximum of 1. For all estimated distributions, I employ a Gaussian kernel and the Sheather and Jones (1991) method for choice of the optimal bandwidth

Table 6 Decomposition of soil erosion by source under Model 3 $(N=90)$

\begin{tabular}{lrrrr}
\hline & Mean & SD & Min & Max \\
\hline Soil loss $(t)$ due to & & & & \\
$\quad$ Erosion control inefficiency & 7.16 & 16.49 & 0.00 & 104.22 \\
$\quad$ Land use inefficiency & 54.89 & 107.53 & 0.00 & 752.17 \\
$\quad$ Environmental allocative & 27.87 & 69.26 & 0.00 & 368.18 \\
$\quad$ inefficiency & & & & \\
Optimal soil loss (t) & 73.05 & 79.94 & 4.33 & 513.47 \\
Actual soil loss $(\mathrm{t})$ & 162.97 & 187.53 & 4.33 & 1038.87 \\
\hline
\end{tabular}

The decomposition of actual soil erosion according to Eq. (26.3) is shown. Reported values are based on a sample of 90 Austrian crop farms observed in 2011

rejected. Regarding EAE, we are unable to reject the hypothesis of identical distributions between Model 1, 2, and 3 at the 5\% significance level.

Table 6 shows that optimal average soil loss according to Model 3 is $73 \mathrm{t}$ per farm in 2011 compared with an actual average soil loss of $163 \mathrm{t}$ per farm. The main source of this inefficiency is the inefficient use of land (contributes $55 \mathrm{t}$ ), followed by an inefficient allocation of inputs (contributes $28 \mathrm{t}$ ). The inefficient implementation of erosion controls contributes only little ( $7 \mathrm{t}$ ) to the overall inefficiency. This is also indicated by the efficiency indices in Table 5, where the average MIE, EAE, and ECE is 0.69, 0.79, and 0.96, respectively. Figure 4 complements Table 6 by showing the decomposition of soil loss by source for all farms.

Table 7 compares the actual, average abatement output and input ratios with the optimal average values according to the solutions associated with Eqs. (22)-(24), that is, Model 3, whereas Optimal 1 considers erosion control, that is, increasing the abatement output, as the single abatement strategy. In addition, Optimal 2 allows for the reduction of land, and Optimal 3 further allows for the substitution of land with labor, intermediate inputs, and capital.

Table 7 indicates that, under Optimal 1, with the actually employed amount of inputs, the average abatement output can be increased from 19 to $26 \mathrm{t}$ per farm, while keeping real total revenues constant. Hence, if farmers consider erosion control as the single available abatement strategy, the efficient implementation of those measures allows reducing the average soil loss by $7 \mathrm{t}$ per farm (cf. Table 6 ) or by $4 \%$ (cf. Table 5). In Optimal 2, the optimal average land use is 42 ha per farm compared with 64 ha actual land use. Since the usage of other inputs remains constant the optimal labor-land, intermediate inputs-land and capital-land ratios increase substantially. Allowing for the substitution of land with other inputs reduces the optimal land use under Optimal 3 to 32 ha per farm and leads to a further increase of the labor-land and intermediate inputs-land ratios.

The results indicate that the same amount of output can be potentially achieved by using substantially less arable land, that is, the optimal average land use is 32 ha per farm compared with 61 ha actual land use. Land use inefficiencies caused, on average, a soil loss of $55 \mathrm{t}$ per farm in 2011, and the substitution of land with labor, capital, and intermediate inputs would have allowed an additional reduction of average soil loss by $28 \mathrm{t}$ per farm. Overall, the results suggest that a considerable reduction of arable land and its conversion into wood- or grassland is potentially achievable without reducing real total revenues. The higher optimal input ratios under Optimal 2 and Optimal 3 suggest an intensification of agriculture on a reduced arable area. 


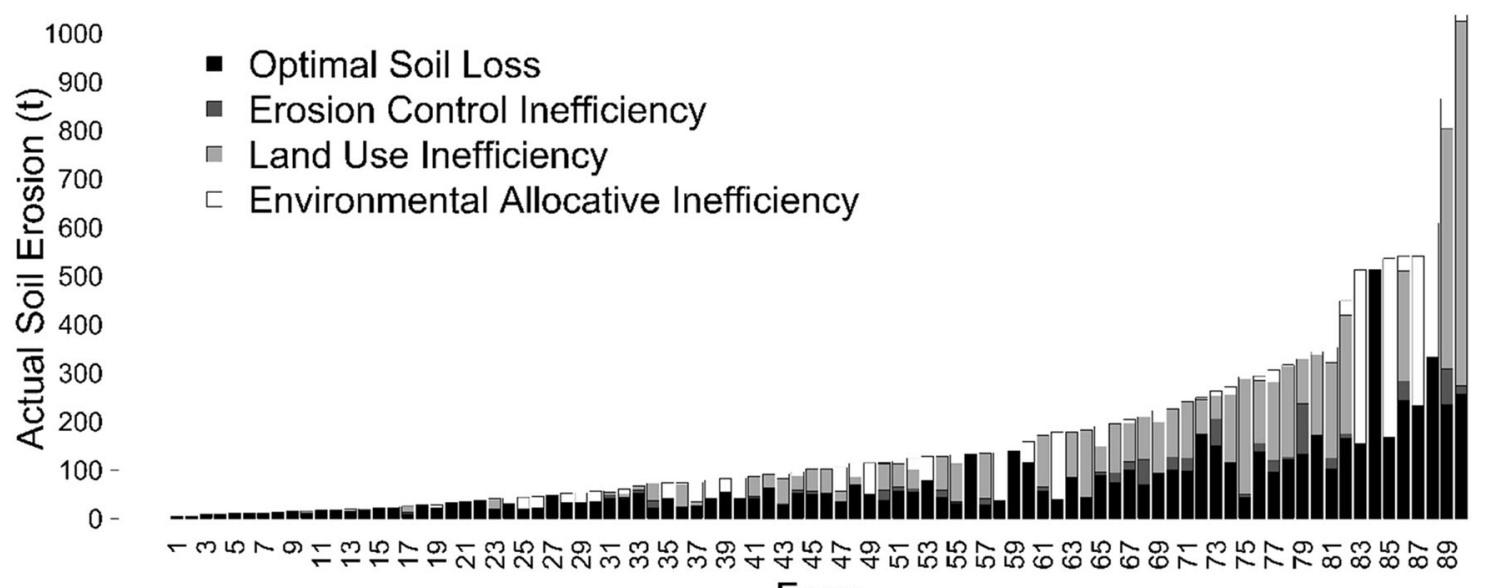

Farm

Fig. 4 Decomposition of actual soil erosion by source for all farms under Model 3 (Eq. (26.3))

Table 7 Optimal vs. observed abatement output and input ratios $(N=90)$

\begin{tabular}{lrrrr}
\hline Variable & Actual & Optimal 1 & Optimal 2 & Optimal 3 \\
\hline Abatement erosion (t) & 18.72 & 25.88 & 8.46 & 3.41 \\
$\begin{array}{l}\text { Input ratios } \\
\quad \text { Labor-land (hours/ha) }\end{array}$ & 38.28 & 38.28 & 61.40 & 76.10 \\
$\begin{array}{l}\text { Intermediate } \\
\text { inputs-land (€/ha) }\end{array}$ & 371.41 & 371.41 & 627.50 & 639.60 \\
$\quad$ Capital-land (€/ha) & 2369.61 & 2369.61 & 3843.92 & 3584.77 \\
\hline
\end{tabular}

Mean values for a sample of 90 Austrian crop farms observed in 2011 are reported. The optimal solution of Model 3 is shown. Optimal 1 considers erosion control as a single abatement strategy. In addition, Optimal 2 allows for the reduction of land, and Optimal 3 considers the substitution of land with labor, intermediate inputs, and capital as further abatement strategy. Mean optimal land use under Optimal 3 is 31.9 ha

\section{Conclusion}

The materials-balance based productive efficiency models and EE measures introduced by Coelli et al. (2007) and Rødseth $(2016,2017)$ produce biased efficiency estimates if the MFCs are non-discretionary and heterogeneous across DMUs. In addition, the Coelli et al. (2007) measure fails to reward emission reductions by emission control. To overcome these shortcomings, this article provides a generalization of Coelli et al.'s (2007) production model by allowing for heterogeneous MFCs and considering emission control as an additional abatement strategy. MFCs are considered to be uncontrollable by the DMUs and may reflect (i) differences of some external environmental factors that govern the transformation of inputs into good and bad outputs or (ii) non-controllable heterogeneities in inputs and outputs (e.g., input or output quality). Based on this, new EE measures and its decomposition are proposed. The new EE measures coincide with the Coelli et al. (2007) measure if the MFCs are homogeneous across all DMUs, none of the producers control emissions, and the MFCs of the desirable outputs are zero. In this context, it is shown that the proposed EE measures can be decomposed into three parts: a part reflecting the efficiency of the emission control activities, a part associated with the efficient use of material inputs and a part reflecting the efficient allocation between material and non-material inputs. These separate effects provide useful insights on the potential sources of environmental inefficiency.

The methodology is illustrated by an empirical application to arable farming using data from 90 Austrian crop farms for the year 2011. The usage of arable land for crop production naturally and inevitably causes soil erosion by water, an undesirable by-product of agriculture production that we want to minimize. ${ }^{19}$ We find evidence of a high potential to reduce soil loss from arable farming without sacrificing output, that is, relatively low levels of EE. On average, farms can potentially achieve the same real revenues with $47 \%$ less soil loss, which reflected a reduction of soil loss from $163 \mathrm{t}$ to $73 \mathrm{t}$ per farm in 2011 . The results are driven by the inefficient usage of agricultural land and the inefficient allocation of inputs toward an overutilization of agricultural area vis-à-vis labor, capital, and other inputs (e.g., fertilizer, pesticide, energy, and seeds). Inefficiencies in the implementation of subsidized erosion control measures, such as planting cover crops, mulch-tillage and direct seeding, are of minor importance. The findings indicate that soil loss can be

\footnotetext{
19 The proposed method might also be applied to EE assessment of livestock farms with respect to nutrient pollution if fertilizer quality is not under managerial control, or the EE analysis of power plants regarding greenhouse gas emissions if switching between fuels is restricted by technical constraints.
} 
reduced at reasonable costs, in terms of forgone output, by using less arable land more intensively. This would allow to set aside a considerable amount of arable land for conservation uses.

Policies aiming to reduce soil erosion should go beyond subsidizing erosion control measures and incentives farmers to take erosion-prone areas with low yield potential out of production, allowing for a land-use change from agricultural land to permanent grass- or woodland. Policies that increase the price of especially erosion-prone, agricultural land relative to other inputs could incentivize farmers to adjust their factor mix, decrease the overexploitation of land and reduce soil loss. This might be achieved, e.g., by a land tax that increases with increasing risk of erosion. Another policy option is to oblige or subsidize farmers to set aside a proportion of their arable land, especially arable land vulnerable to erosion, and devote it to erosion-friendly uses (e.g., green manure).

Finally, it is important that actions taken against one particular environmental problem do not increase other problems. Agricultural production not only affects soil erosion, but also nutrient and pesticide residue and runoffs, greenhouse gases emissions, water usage, and biodiversity. A limitation of this study is that only one undesirable output is considered. Future research should extend this analysis to multiple bad outputs and analyze the trade-offs among them.

Acknowledgements The author gratefully acknowledges the valuable comments received on earlier versions of this paper from two anonymous referees, Klaus Salhofer, Martin Odening, Mikuláš Luptáčik, Andreas Niedermayr, Bernhard Mahlberg, Alexander Schnabl, the participants of the Webinar organized by the research unit FORLand on July 16, 2020, the participants of the virtual North American Productivity Workshop 2021 in June 2021, the participants of the 31st European Conference on Operational Research in Athens in July 2021, the participants of the virtual XVI European Association of Agricultural Economics Congress 2021 in July 2021, and the participants of the virtual 31st Triennial International Conference of Agricultural Economists 2021 in August 2021. I am grateful to the Austrian Federal Ministry for Sustainability and Tourism for providing the confidential data used in this study.

Funding The author would like to thank the Austrian Science Fund (FWF) for funding the project under project number I 3505-G27. The research was conducted as part of the Research Group FORLand supported by the Deutsche Forschungsgemeinschaft (DFG, German Research Foundation)—317374551 (https://www.forland.hu-berlin. de).

\section{Compliance with ethical standards}

Conflict of interest The author declares no competing interests.

Publisher's note Springer Nature remains neutral with regard to jurisdictional claims in published maps and institutional affiliations.
Open Access This article is licensed under a Creative Commons Attribution 4.0 International License, which permits use, sharing, adaptation, distribution and reproduction in any medium or format, as long as you give appropriate credit to the original author(s) and the source, provide a link to the Creative Commons license, and indicate if changes were made. The images or other third party material in this article are included in the article's Creative Commons license, unless indicated otherwise in a credit line to the material. If material is not included in the article's Creative Commons license and your intended use is not permitted by statutory regulation or exceeds the permitted use, you will need to obtain permission directly from the copyright holder. To view a copy of this license, visit http://creativecommons. org/licenses/by/4.0/.

\section{Appendix A}

\section{Proof of proposition 1}

Step 1: Rewrite Rødseth's (2016) emission minimizing problem in Eq. (8) by inserting the equality constraint for $b^{c}$ in the objective function

$$
\begin{array}{ll}
\min _{\lambda, \varepsilon, x} & b_{I I}^{c *}=\sum_{i=1}^{N} \lambda_{i} b_{i}^{c}+\varepsilon_{b^{c}} \\
\text { s.t. } \quad & x^{k}=\sum_{i=1}^{N} \lambda_{i} x_{i}^{k}+\varepsilon_{x^{k}} \quad k=1, \ldots, K \\
& y_{o}^{m}=\sum_{i=1}^{N} \lambda_{i} y_{i}^{m}-\varepsilon_{y^{m}}, \quad m=1, \ldots, M \\
& \sum_{k=1}^{K} u^{k} \varepsilon_{x^{k}}+\sum_{m=1}^{M} v^{m} \varepsilon_{y^{m}}-\varepsilon_{b^{c}}=0 \\
& \sum_{i=1}^{N} \lambda_{i}=1 \\
& \lambda_{i}, \varepsilon_{x^{k}}, \varepsilon_{y^{m}}, \varepsilon_{a} \geq 0, \forall i, k, m .
\end{array}
$$

Step 2: Exploit the summing up restriction for the slack variables $\sum_{k=1}^{K} u^{k} \varepsilon_{x^{k}}+\sum_{m=1}^{M} v^{m} \varepsilon_{y^{m}}-\varepsilon_{b^{c}}=0$ and that the convexity constraints of the inputs and desirable outputs can be rewritten as $\varepsilon_{x^{k}}=x^{k}-\sum_{i=1}^{N} \lambda_{i} x_{i}^{k}, k=$ $1, \ldots, K, \quad$ and $\varepsilon_{y^{m}}=\sum_{i=1}^{N} \lambda_{i} y_{i}^{m}-y_{o}^{m}, m=1, \ldots, M, \quad$ to rewrite (A1) as

$$
\begin{array}{ll}
\min _{\lambda, \varepsilon, x} & \sum_{i=1}^{N} \lambda_{i} b_{i}^{c}+\sum_{k=1}^{K} u^{k}\left(x^{k}-\sum_{i=1}^{N} \lambda_{i} x_{i}^{k}\right)+\sum_{m=1}^{M} v^{m}\left(\sum_{i=1}^{N} \lambda_{i} y_{i}^{m}-y_{o}^{m}\right) \\
\text { s.t. } & x^{k}=\sum_{i=1}^{N} \lambda_{i} x_{i}^{k}+\varepsilon_{x^{k}} \quad k=1, \ldots, K \\
& y_{o}^{m}=\sum_{i=1}^{N} \lambda_{i} y_{i}^{m}-\varepsilon_{y^{m}}, \quad m=1, \ldots, M \\
& \sum_{i=1}^{N} \lambda_{i}=1 \\
& \lambda_{i}, \varepsilon_{x^{k}}, \varepsilon_{y^{m}}, \varepsilon_{a} \geq 0, \forall i, k, m .
\end{array}
$$

Step 3: Rewrite the objective function in (A2) by substituting $b_{i}^{c}$ with the expression of controlled emission given 
by Eq. (2)

$$
\begin{aligned}
& \sum_{i=1}^{N} \lambda_{i}\left(\sum_{k=1}^{K} u^{k} x_{i}^{k}-\sum_{m=1}^{M} v^{m} y_{i}^{m}-a_{i}\right) \\
& +\sum_{k=1}^{K} u^{k}\left(x^{k}-\sum_{i=1}^{N} \lambda_{i} x_{i}^{k}\right)+\sum_{m=1}^{M} v^{m}\left(\sum_{i=1}^{N} \lambda_{i} y_{i}^{m}-y_{o}^{m}\right) \\
& =\sum_{k=1}^{K} u^{k} x^{k}-\sum_{m=1}^{M} v^{m} y_{o}^{m}-\sum_{i=1}^{N} \lambda_{i} a_{i} .
\end{aligned}
$$

Step 4: Insert (A3) into (A2)

$$
\begin{array}{ll}
\min _{\lambda, \varepsilon, x} & \sum_{k=1}^{K} u^{k} x^{k}-\sum_{m=1}^{M} v^{m} y_{o}^{m}-\sum_{i=1}^{N} \lambda_{i} a_{i} \\
\text { s.t. } & x^{k}=\sum_{i=1}^{N} \lambda_{i} x_{i}^{k}+\varepsilon_{x^{k}} \quad k=1, \ldots, K \\
& y_{o}^{m}=\sum_{i=1}^{N} \lambda_{i} y_{i}^{m}-\varepsilon_{y^{m}}, \quad m=1, \ldots, M \\
& \sum_{i=1}^{N} \lambda_{i}=1 \\
& \lambda_{i}, \varepsilon_{x^{k}}, \varepsilon_{y^{m}}, \varepsilon_{a} \geq 0, \forall i, k, m .
\end{array}
$$

The emission minimization problem accounting for abatement activities that is developed in this article, that is, Eq. (7), can be rewritten by inserting the equality constraint for $a$ into the objective function

$$
\begin{gathered}
\min _{\lambda, \varepsilon, x} \sum_{k=1}^{K} u^{k} x^{k}-\sum_{m=1}^{M} v^{m} y_{o}^{m}-\sum_{i=1}^{N} \lambda_{i} a_{i}+\varepsilon_{a} \\
\text { s.t } \quad x^{k}=\sum_{i=1}^{N} \lambda_{i} x_{i}^{k}+\varepsilon_{x^{k}}, \quad k=1, \ldots, K \\
y_{o}^{m}=\sum_{i=1}^{N} \lambda_{i} y_{i}^{m}-\varepsilon_{y^{m}}, m=1, \ldots, M \\
\sum_{i=1}^{N} \lambda_{i}=1 \\
\lambda_{i}, \varepsilon_{x^{k}}, \varepsilon_{y^{m}}, \varepsilon_{a} \geq 0, \forall i, k, m .
\end{gathered}
$$

Hence, (A4), the model developed by Rødseth (2016), and (A5), my model, deliver exactly the same solution if the slack of the abatement output in Eq. (7), $\varepsilon_{a}$, is zero.

\section{Appendix B}

Linkage between RUSLE model and materials balance equation

\section{a. Materials balance equation}

$b^{u c}=u x-v y$

$$
\begin{aligned}
& b^{c}=u x-v y-a \\
& \Leftrightarrow \quad a=b^{u c}-b^{c}
\end{aligned}
$$

\section{b. RUSLE model}

$$
\begin{aligned}
& A=R K S L C P \quad \ldots \text { soil loss in } / \text { ha/year } \\
& A^{P=1}=R K S L C \quad \ldots \text { soil loss in } / \text { ha/year if } P=1, \\
& \\
& \quad \begin{array}{l}
\text { i.e., no erosion controls are implemented }
\end{array}
\end{aligned}
$$

\section{c. Definition of variables for empirical model}

$x=\left(\begin{array}{l}\text { Land in ha, Labor in } A W U, \\ \text { Capital in } €, \text { Intermediate Inputs in } €\end{array}\right)^{T}$

$u=\left(u_{\text {Land }}, 0,0,0\right)$

$y=$ Total revenue in $€$

$v=0$

$b^{u c}=R K S L C *$ Land $\ldots$ soil loss without erosion controls in $t /$ year

$b^{c}=R K S L C P *$ Land $\ldots$ soil loss with erosion controls in t/year

$a=b^{u c}-b^{c}=$ RKSLCLand $*(1-P) \quad \ldots$ avoided soil loss by erosion controls in $t /$ year

\section{d. Derivation of $\mathbf{u}$}

$b^{c}=u x-v y-a \stackrel{\text { Eq. (B9) }}{=} u x-a \stackrel{\text { Eq. (B6), (B7) }}{=} u_{\text {Land }}$ Land $-a$

$\stackrel{\mathrm{Eq} .(\mathrm{B} 11),(\mathrm{B} 12)}{\Leftrightarrow}{ }^{\mathrm{R} K S L C P L \text { Land }}=u_{\text {Land }}$ Land - RKSLCLand $*(1-P)$

$\Leftrightarrow \quad R K S L C P L$ Land + RKSLCLand - RKSLCPLand $=u_{\text {Land }}$ Land

$\Leftrightarrow \quad$ RKSLCLand $=u_{\text {Land }}$ Land

$\Leftrightarrow u_{\text {Land }}=R K S L C \stackrel{\text { Eq.(B5) }}{=} A^{P=1} \quad \ldots$ soil loss in $t /$ ha $/$ year if $P=1$, i.e., uncontrolled erosion in $\mathrm{t} / \mathrm{h}$ / $/$ year 


\section{Appendix C}

Table 8 Distribution hypothesis tests

\begin{tabular}{lll}
\hline Null hypothesis $\left(\mathrm{H}_{0}\right)$ & Bootstrap $p$-value & $\begin{array}{l}\text { Conclusion for } \\
\text { testing } \mathrm{H}_{0}\end{array}$ \\
\hline 1. $\mathrm{f}(\mathrm{EE} 1)=\mathrm{g}(\mathrm{EE} 2)$ & 0.0000 & Rejected \\
2. $\mathrm{f}(\mathrm{EE} 1)=\mathrm{g}(\mathrm{EE} 3)$ & 0.8710 & Not rejected \\
3. $\mathrm{f}(\mathrm{EE} 2)=\mathrm{g}(\mathrm{EE} 3)$ & 0.0000 & Rejected \\
4. $\mathrm{f}(\mathrm{ECE} 1)=\mathrm{g}(\mathrm{ECE} 2)$ & 0.0000 & Rejected \\
5. $\mathrm{f}(\mathrm{ECE} 1)=\mathrm{g}(\mathrm{ECE} 3)$ & 0.9754 & Not rejected \\
6. $\mathrm{f}(\mathrm{ECE} 2)=\mathrm{g}(\mathrm{ECE} 3)$ & 0.0002 & Rejected \\
7. $\mathrm{f}(\mathrm{MIE} 1)=\mathrm{g}(\mathrm{MIE} 2)$ & 0.0034 & Rejected \\
8. $\mathrm{f}(\mathrm{MIE} 1)=\mathrm{g}(\mathrm{MIE} 3)$ & 1.0000 & Not rejected \\
9. $\mathrm{f}(\mathrm{MIE} 2)=\mathrm{g}(\mathrm{MIE} 3)$ & 0.0000 & Rejected \\
10. $\mathrm{f}(\mathrm{EAE} 1)=\mathrm{g}(\mathrm{EAE} 2)$ & 0.2550 & Not rejected \\
11. $\mathrm{f}(\mathrm{EAE} 1)=\mathrm{g}(\mathrm{EAE} 3)$ & 0.9532 & Not rejected \\
12. $\mathrm{f}(\mathrm{EAE} 2)=\mathrm{g}(\mathrm{EAE} 3)$ & 0.0600 & Not rejected
\end{tabular}

Results are based on bootstrapped Li (1996) tests with 5000 bootstrap replications. The function $\mathrm{f}($.$) and \mathrm{g}($.$) are Gaussian kernel distributions$ using the Silverman's (1986) rule of thumb bandwidth. Rejection of the null-hypothesis is based on a p-value threshold of $0.05(5 \%$ significance level)

\section{References}

Adhikari B, Nadella K (2011) Ecological economics of soil erosion: a review of the current state of the knowledge. Ann NY Acad Sci 1219:134-152. https://doi.org/10.1111/j.1749-6632.2010.05910.x

Ait Sidhoum A, Serra T, Latruffe L (2020) Measuring sustainability efficiency at farm level: a data envelopment analysis approach. Eur Rev Agric Econ 47:200-225. https://doi.org/10.1093/erae/jbz015

Ayres RU, Kneese AV (1969) Production, consumption and externalities. Am Econ Rev 59:282-297

Banker RD, Charnes A, Cooper WW (1984) Some models for estimating technical and scale inefficiencies in data envelopment analysis. Manag Sci 30:1078-1092. https://doi.org/10.1287/mnsc.30.9.1078

Bi GB, Shao Y, Song W, Yang F, Luo Y (2018) A performance evaluation of China's coal-fired power generation with pollutant mitigation options. J Clean Prod 171:867-876. https://doi.org/10. 1016/j.jclepro.2017.09.271

BMLFUW [Bundesministerium für Land- und Forstwirtschaft, Umwelt, und Wasserwirtschaft] (2009) ÖPUL 2007, Sonderrichtlinie des BMLFUW für das österreichische Programm zur Förderung einer umweltgerechten extensiven und den natürlichen Lebensraum schützenden Landwirtschaft. Bundesministerium für Land- und Forstwirtschaft, Umwelt und Wasserwirtschaft (BMLFUW). Vienna: BMLFUW

Bogetoft P, Otto L (2011) Benchmarking with DEA, SFA and R. Springer Science+Business Media, New York, NY, https://doi. org/10.1007/978-1-4419-7961-2

Bostian M, Färe R, Grosskopf S, Lundgren T (2016) Environmental investment and firm performance: a network approach. Energy Econ 57:243-255. https://doi.org/10.1016/j.eneco.2016.05.013

Bostian M, Färe R, Grosskopf S, Lundgren T (2019) Prevention or cure? Abatement efficiency in a network technology. CERE
Working Paper 2019:11. Available at SSRN: https://ssrn.com/a bstract $=3440289$ or https://doi.org/10.2139/ssrn.3440289

Charnes A, Cooper WW (1962) Programming with linear fractional functionals. Nav Res Logist Q 9:181-186

Coelli T, Lauwers L, Huylenbroeck GV (2007) Environmental efficiency measurement and the materials balance condition. J Prod Anal 28:3-12. https://doi.org/10.1007/s11123-007-0052-8

Dakpo KH (2016) On modelling pollution-generating technologies: a new formulation of the by-production approach. Working Paper SMART_LERECO No. 16-06. https://doi.org/10. 22004/ag.econ.245191

Dakpo KH, Jeanneaux P, Latruffe L (2016) Modelling pollutiongenerating technologies in performance benchmarking: recent developments, limits and future prospects in the nonparametric framework. Eur J Oper Res 250:347-359. https://doi.org/10. 1016/j.ejor.2015.07.024

Dakpo KH, Jeanneaux P, Latruffe L (2017) Greenhouse gas emissions and efficiency in French sheep meat farming: a non-parametric framework of pollution-adjusted technologies. Eur Rev Agric Econ 44:33-65. https://doi.org/10.1093/erae/jbw013

EC [European Commission] (2001) A sustainable Europe for a better world: a European Union strategy for sustainable development. Commission's proposal to the Gothenburg European Council. COM (2001)264 final, 15 May 2001.

Eder A, Salhofer K, Scheichel E (2021) Land tenure, soil conservation, and farm performance: an eco-efficiency analysis of Austrian crop farms. Ecol Econ 180. https://doi.org/10.1016/j.ecolecon. 2020.106861

Färe R, Grosskopf S (2003) Nonparametric productivity analysis with undesirable outputs: comment. Am J Agr Econ 85:1070-1074. https://doi.org/10.1111/1467-8276.00510

Färe R, Grosskopf S (2004) Modeling undesirable factors in efficiency evaluation: comment. Eur J Oper Res 157:242-245. https://doi. org/10.1016/S0377-2217(03)00191-7

Färe R, Grosskopf S, Lovell CAK, Pasurka C (1989) Multilateral productivity comparisons when some outputs are undesirable: a nonparametric approach. Rev Econ Stat 71:90-98. https://doi.org/ $10.2307 / 1928055$

Färe R, Grosskopf S, Pasurka C (1986) Effects on relative efficiency in electric power generation due to environmental controls. Resour Energy 8:167-184. https://doi.org/10.1016/0165-0572(86)90016-2

Färe R, Grosskopf S, Pasurka C (2013) Joint production of good and bad outputs with a network application. In: Shogren J (ed) Encyclopedia of energy, natural resources and environmental economics, vol 2. Elsevier, Amsterdam, p 109-118. 10.1016/ B978-0-12-375067-9.00134-0

Färe R, Primont D (1995) Multi-output production and duality: Theory and applications. Kluwer Academic Publishers, Boston/London/ Dordrecht, 10.1007/978-94-011-0651-1

Førsund FR (2009) Good modelling of bad outputs: pollution and multiple-output production. Int Rev Environ Resour Econ 3:1-38. https://doi.org/10.1561/101.00000021

Førsund FR (2018) Multi-equation modelling of desirable and undesirable outputs satisfying the materials balance. Empir Econ 54:67-99. https://doi.org/10.1007/s00181-016-1219-9

Frisch R (1965) Theory of production. Reidel Publishing Company, Dordrecht

Graves AR, Morris J, Deeks LK, Rickson RJ, Kibblewhite MG, Harris JA, Farewell TS, Truckle I (2015) The total costs of soil degradation in England and Wales. Ecol Econ 119:399-413. https:// doi.org/10.1016/j.ecolecon.2015.07.026

Griggs D, Stafford-Smith M, Gaffney O, Rockström J, Öhman MC, Shyamsundar P, Steffen W, Glaser G, Kanie N, Noble I (2013) Policy: sustainable development goals for people and planet. Nature 495:305-307. https://doi.org/10.1038/495305a 
Hailu A, Veeman TS (2001) Non-parametric productivity analysis with undesirable outputs: an application to the Canadian pulp and paper industry. Am J Agr Econ 83:605-616. https://doi.org/10. 1111/0002-9092.00181

Hampf B (2014) Separating environmental efficiency into production and abatement efficiency: a nonparametric model with application to US power plants. J Prod Anal 41:457-473. https://doi.org/10. 1007/s11123-013-0357-8

Hampf B (2018) Measuring inefficiency in the presence of bad outputs: does the disposability assumption matter? Empir Econ 54:101-127. https://doi.org/10.1007/s00181-016-1204-3

Hampf B, Rødseth KL (2015) Carbon dioxide emission standards for U.S. power plants: an efficiency analysis perspective. Energy Econ 50:140-153. https://doi.org/10.1016/j.eneco. 2015.04.001

Hampf B, Rødseth KL (2017) Optimal profits under environmental regulation: the benefits from emission intensity averaging. Ann Oper Res 255:367-390. https://doi.org/10.1007/s10479-0152020-4

Hampf B, Rødseth KL (2019) Environmental efficiency measurement with heterogeneous input quality: a nonparametric analysis of $U$. S. power plants. Energy Econ 81:610-625. https://doi.org/10. 1016/j.eneco.2019.04.031

Hoang VH, Alauddin M (2012) Input-orientated data envelopment analysis framework for measuring and decomposing economic, environmental and ecological efficiency: an application to OECD agriculture. Environ Resour Econ 51:431-452. https://doi.org/10. 1007/s10640-011-9506-6

Hoang VH, Coelli T (2011) Measurement of agricultural total factor productivity growth incorporating environmental factors: a nutrients balance approach. J Environ Econ Manag 62:462-474. https://doi.org/10.1016/j.jeem.2011.05.009

Hoang VH, Nguyen TT (2013) Analysis of environmental efficiency variation: a materials balance approach. Ecol Econ 86:37-46. https://doi.org/10.1016/j.ecolecon.2012.10.014

Hoang VH, Rao DSP (2010) Measuring and decomposing sustainable efficiency in agricultural production: a cumulative exergy balance approach. Ecol Econ 69:1765-1776. https://doi.org/10.1016/j. ecolecon.2010.04.014

Keesstra SD, Mol G, de Leeuw J, Okx J, de Cleen M, Visser S (2018) Soil-related sustainable development goals: four concepts to make land degradation neutrality and restoration work. Land 7:133. https://doi.org/10.3390/land7040133

Kneese AV, Ayres RU, d'Arge RC (1970) Economics and the environment: a materials balance approach. John Hopkins Press, Baltimore, 10.4324/9781315682136

Kuosmanen T, Kortelainen M (2005) Measuring eco-efficiency of production with data envelopment analysis. J Ind Ecol 9:59-72. https://doi.org/10.1162/108819805775247846

Lauwers L (2009) Justifying the incorporation of the materials balance principle into frontier-based eco-efficiency models. Ecol Econ 68:1605-1614. https://doi.org/10.1016/j.ecolecon.2008.08.022

Lei F (2020) Opening the "black box" of environmental production technology in a nonparametric analysis. Eur J Oper Res 286:769-780. https://doi.org/10.1016/j.ejor.2020.03.043

Li Q (1996) Nonparametric testing of closeness between two unknown distribution functions. Econom Rev 15:261-274. https://doi.org/ 10.1080/07474939608800355

Lovell CAK, Pastor JT, Turner JA (1995) Measuring macroeconomic performance in the OECD: a comparison of European and nonEuropean countries. Eur J Oper Res 87:507-518. https://doi.org/ 10.1016/0377-2217(95)00226-X

Lozano S (2015) A joint-inputs network DEA approach to production and pollution-generating technologies. Expert Syst Appl 42:7960-7968. https://doi.org/10.1016/j.eswa.2015.06.023
Murty S, Russell RR, Levkoff SB (2012) On modelling pollutiongenerating technologies. J Environ Econ Manage 64:117-135. https://doi.org/10.1016/j.jeem.2012.02.005

Nguyen TT, Hoang VN, Seo B (2012) Cost and environmental efficiency of rice farms in South Korea. Agric Econ 43:369-378. https://doi.org/10.1111/j.1574-0862.2012.00589.x

Panagos P, Borrelli P, Meusburger K et al. (2015a) Estimating the soil erosion cover-management factor at European scale. Land Use Policy 48:38-50. https://doi.org/10.1016/j.landusepol. 2015.05.021

Panagos P, Borreli P, Meusburger K et al. (2015b) Modelling the effect of support practices (P-factor) on the reduction of soil erosion by water at European scale. Environ Sci Policy 51:23-34. https://doi.org/10.1016/j.envsci.2015.03.012

Panagos P, Borreli P, Posen J et al. (2015c) The new assessment of soil loss by water erosion in Europe. Environ Sci Policy 54:438-447. https://doi.org/10.1016/j.envsci.2015.08.0122015n

Panagos P, Borrelli P, Standardi G et al. (2018) Cost of agricultural productivity loss due to soil erosion in the European Union: from direct cost evaluation approaches to the use of macroeconomic models. Land Degrad Dev 29:471-484. https://doi.org/10.1002/ ldr.2879

Pethig R (2003) The 'materials balance' approach to pollution: its origin, implications and acceptance. University of Siegen, Economic Discussion Paper No. 105-03

Pethig R (2006) Non-linear production, abatement, pollution and materials balance reconsidered. J Environ Econ Manage 51:185-204. https://doi.org/10.1016/j.jeem.2005.01.006

Picazo-Tadeo AJ, Gómez-Limón JA, Reig-Martínez E (2012a) Ecoefficiency assessment of olive farms in Andalusia. Land use Policy 29:395-406. https://doi.org/10.1016/j.landusepol.2011.08.004

Picazo-Tadeo AJ, Gómez-Limón JA, Beltrán-Esteve M (2012b) Assessing eco-efficiency with directional distance functions. Eur J Oper Res 220:798-809. https://doi.org/10.1016/j.ejor.2012.02.025

Picazo-Tadeo AJ, Gómez-Limón JA, Beltrán-Esteve M, Reig-Martínez E (2014) A meta frontier directional distance function approach to assessing eco-efficiency. J Prod Anal 41:69-83. https://doi.org/10.1007/s11123-012-0334-7

Pimentel DC, Harvey P, Resosudarmo K et al. (1995) Environmental and economic costs of soil erosion and conservation benefits. Science 267:1117-1122. https://doi.org/10.1126/science.267.5201.1117

Podinovski VV, Kuosmanen T (2011) Modelling weak disposability in data envelopment analysis under relaxed convexity assumptions. Eur J Oper Res 211:577-585. https://doi.org/10.1016/j.ejor.2010. 12.003

Ray SC, Mukherjee K, Venkatesh A (2018) Nonparametric measures of efficiency in the presence of undesirable outputs: a byproduction approach. Empir Econ 54:31-65. https://doi.org/10. 1007/s00181-017-1234-5

Renard K, Foster G, Weesies G, McCool D, Yoder D (1997) Predicting soil erosion by water: a guide to conservation planning with the revised universal soil loss equation (RUSLE). US Department of Agriculture (USDA), USDA, Washington, DC

Rødseth KL (2016) Environmental efficiency measurement and the materials balance condition reconsidered. Eur J Oper Res 250:342-346. https://doi.org/10.1016/j.ejor.2015.10.061

Rødseth KL (2017) Axioms of a polluting technology: a materials balance approach. Environ Resour Econ 67:1-22. https://doi.org/ 10.1007/s10640-015-9974-1

Ruggiero J (1996) On the measurement of technical efficiency in the public sector. Eur J Oper Res 90:553-565. https://doi.org/10. 1016/0377-2217(94)00346-7

Ruggiero J (1998) Non-discretionary inputs in data envelopment analysis. Eur J Oper Res 111:461-469. https://doi.org/10.1016/ S0377-2217(97)00306-8 
Seiford LM, Zhu J (2002) Modeling undesirable factors in efficiency evaluation. Eur J Oper Res 142:16-20. https://doi.org/10.1016/ S0377-2217(01)00293-4

Serra T, Chambers RG, Lansink AO (2014) Measuring technical and environmental efficiency in a state-contingent technology. Eur J Oper Res 236:706-717. https://doi.org/10.1016/j.ejor.2013.12.037

Sheather SJ, Jones MC (1991) A reliable data based bandwidth selection method for kernel density estimation. J R Stat Soc Ser. B 53:683-990

Silverman BW (1986) Density Estimation for Statistics and Data Analysis. Chapman and Hall, London

Verheijen FGA, Jones RJA, Rickson RJ, Smith CJ (2009) Tolerable versus actual soil erosion rates in Europe. Earth-Sci Rev 94:23-38. https://doi.org/10.1016/j.earscirev.2009.02.003

Wang K, Wei YM, Huang Z (2018) Environmental efficiency and abatement efficiency measurements of China's thermal power industry: A data envelopment analysis based materials balance approach. Eur J Oper Res 269:35-50. https://doi.org/10.1016/j. ejor.2017.04.053

Welch E, Barnum D (2009) Joint environmental and cost efficiency analysis of electricity generation. Ecol Econ 68:2336-2343. https://doi.org/10.1016/j.ecolecon.2009.03.004

Wpa GmbH and BAW(2009) Abschätzung des Bodenabtrags in Österreich und Integration der Daten in die INVEKOS Datenbank. Wpa Beratende Ingenieure (Wpa $\mathrm{GmbH}$ ) and Bundesamt für Wasserwirtschaft (BAW). Wpa GmbH and BAW, Vienna, https://gruenerbericht.at/cm4/jdownload/download/28-studien/ 589-23-abschaetzung-bodenabtrag-endbericht. Accessed 21 July 2020

Young R, Orsini S, Fitzpatrick I (2015) Soil degradation: a major threat to humanity. Sustainable Food Trust, Bristol, UK 